\title{
Can Learning Explain Boom-Bust Cycles in Asset Prices? An Application to the US Housing Boom
} Caines, Colin

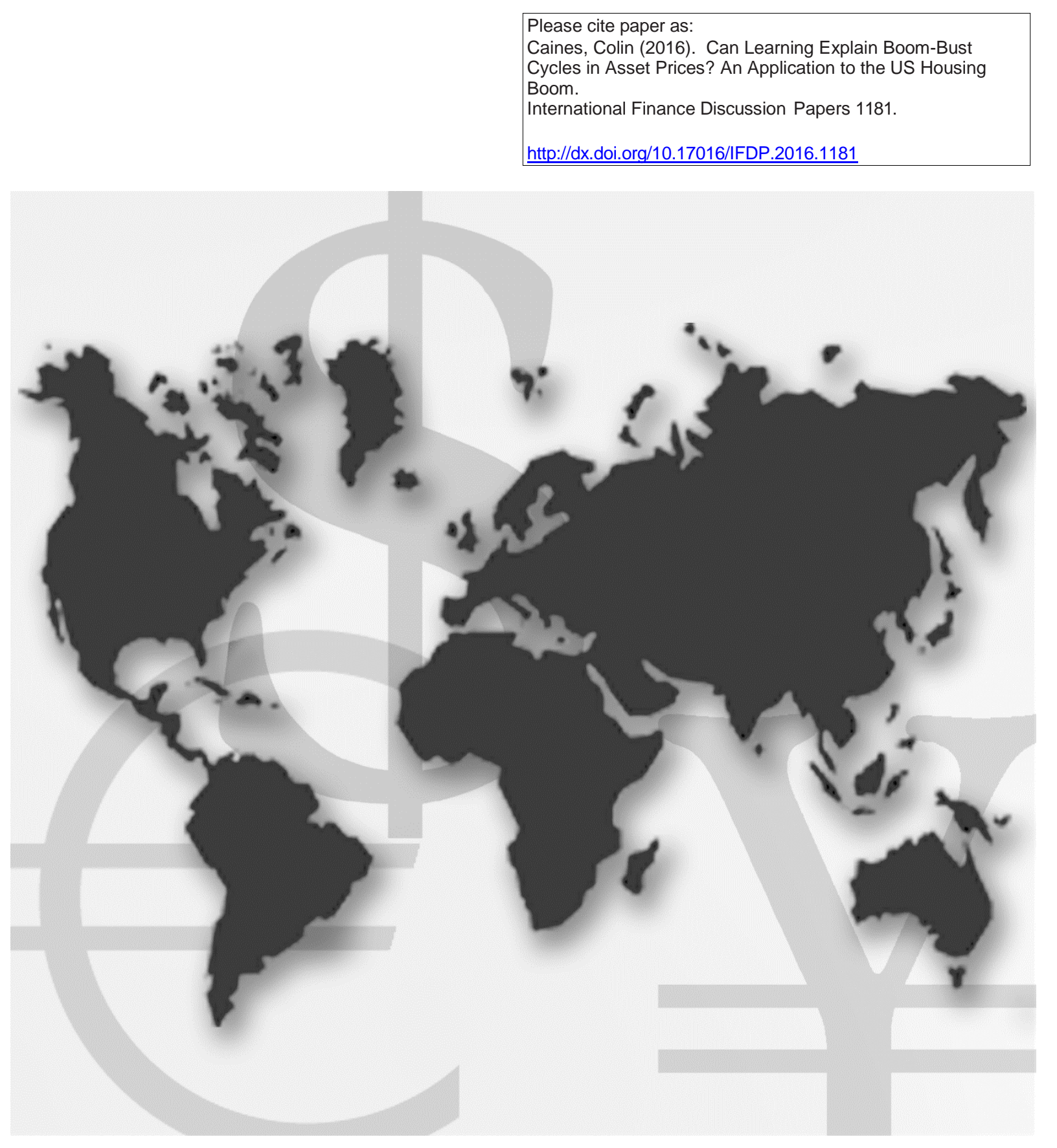

\section{International Finance Discussion Papers}

Board of Governors of the Federal Reserve System

Number 1181

October 2016 


\section{Board of Governors of the Federal Reserve System \\ International Finance Discussion Papers}

Number 1181

October 2016

Can Learning Explain Boom-Bust Cycles In Asset Prices? An Application to the US Housing Boom

\section{Colin Caines}

NOTE: International Finance Discussion Papers are preliminary materials circulated to stimulate discussion and critical comment. References to International Finance Discussion Papers (other than an acknowledgment that the writer has had access to unpublished material) should be cleared with the author or authors. Recent IFDPs are available on the Web at www.federalreserve.gov/pubs/ifdp/. This paper can be downloaded without charge from Social Science Research Network electronic library at www.ssrn.com. 


\title{
Can Learning Explain Boom-Bust Cycles In Asset Prices? An Application to the US Housing Boom
}

\author{
Colin Caines*
}

\begin{abstract}
Explaining asset price booms poses a difficult question for researchers in macroeconomics: how can large and persistent price growth be explained in the absence large and persistent variation in fundamentals? This paper argues that boom-bust behavior in asset prices can be explained by a model in which boundedly rational agents learn the process for prices. The key feature of the model is that learning operates in both the demand for assets and the supply of credit. Interactions between agents on either side of the market create complementarities in their respective beliefs, providing an additional source of propagation. In contrast, the paper shows why learning involving only one side on the market, which has been the focus of most of the literature, cannot plausibly explain persistent and large price booms. Quantitatively, the model explains recent experiences in US housing markets. A single unanticipated mortgage rate drop generates 20 quarters of price growth whilst capturing the full appreciation in US house prices in the early 2000s. The model is able to generate endogenous liberalizations in household lending conditions during price booms, consistent with US data, and replicates key volatilities of housing market variables at business cycle frequencies.
\end{abstract}

Keywords: learning, non-rational expectations, house prices, boom-bust cycles

JEL classifications: E30, E17, D83, G12, R30

\footnotetext{
* The author is a staff economist in the Division of International Finance, Board of Governors of the Federal Reserve System, Washington, D.C. 20551 U.S.A. The views in this paper are solely the responsibility of the author and should not be interpreted as reflecting the views of the Board of Governors of the Federal Reserve System or of any other person associated with the Federal Reserve System. The email address of the author is colin.c.caines@frb.gov. The author would like to thank Paul Beaudry, Amartya Lahiri, Jesse Perla, Yaniv Yedid-Levi, Henry Siu, Fabian Winkler, Bruce Preston, as well as the Social Sciences and Humanities Research Council.
} 


\section{Introduction}

Following the financial crisis of 2008 there has been an intense focus on the tendency of markets to generate boom-bust patterns in asset prices. Explaining these episodes poses a difficult question for researchers: how can large and persistent price growth be explained in the absence of large and persistent exogenous variation? Across a wide range of settings it has proven difficult to identify market fundamentals or frictions that can explain price booms as well as asset price volatility more generally. This paper argues that boombust behavior in asset prices can be explained by a model in which boundedly rational agents learn the process for prices. The key feature of the model is that, in contrast with the literature, learning operates in both the demand for assets and the supply of credit. Propagation comes from the interaction between the two sets of agents in the model, which creates complementarities in their respective beliefs. The quantitative performance of the model is evaluated in the context of recent experiences in US housing markets. A single unanticipated mortgage rate drop, consistent with that observed in the early 2000s, generates 20 quarters of house price growth whilst capturing the full appreciation in US housing in the early 2000s.

The novel feature of this work is that it allows for learning in the credit supply problem facing lenders. This is in contrast to canonical asset pricing models with learning that restrict subjective beliefs to the demand side of the market. Models of bounded rationality allow for the possibility of feedback loops to exist between subjective beliefs and observed outcomes. In order for such environments to generate large and persistent asset price growth in response to a small set of shocks, beliefs need to exhibit two properties. First, subjective beliefs must be highly responsive to observed shocks. The response of outcomes to shifts in beliefs must be of sufficient size to generate subsequent belief shifts. Second, the belief process itself must be sufficiently persistent to prevent the episode from dying out quickly. A contribution of this paper is to show that in models with only demand side learning, there exists a trade-off between these two properties. In other words, increasing the elasticity of beliefs with respect to shocks comes at the cost of decreasing the persistence of these beliefs. As a result of this trade-off such models struggle to explain asset price booms.

Next, the paper shows that this trade-off in the formation of the belief process can be broken by extending bounded rationality to credit suppliers. When learning about prices operates in both the demand side and credit supply side of the market there are complementarities in the beliefs of buyers and lenders. An increase in buyers' price forecasts increases the capital gains they expect to receive on their assets, driving up demand. An increase in lenders' price forecasts decreases the default rate they expect to face on 
their assets, leading to relaxed lending conditions. Each of these actions drive up prices, and through the learning mechanism further increase the price forecasts of each type of agent. The paper shows that this complementarity loosens the trade-off between generating beliefs that are both persistent and responsive.

Finally, the paper shows that this mechanism can quantitatively capture many properties of US housing markets. The full appreciation in US housing seen in the early 2000s can be explained with observed mortgage rate movements. The calibrated model is also shown to replicate key volatilities of housing market variables at business cycle frequencies. Furthermore, the paper explains observed comovements in house prices and household leverage. The model developed here is able to endogenously generate substantial liberalizations in households' borrowing environment concurrent with periods of prolonged price growth.

The paper is structured as follows. Section 2 provides an overview of the literature in which this work is placed as well as a discussion of the recent experience in US housing markets. Section 3 presents the main model, outlining the microfoundations of agents' beliefs, discussing the decision problem and optimality conditions of households and lenders, and finally providing an equilibrium for the model under learning. A discussion of the model's calibration is to be found in section 4. Section 5 presents the analytical findings of the paper and demonstrates how the presence of bounded rationality in both the demand for housing and the supply of credit breaks a trade-off between the persistence of beliefs and the sensitivity of beliefs to shocks that exists in traditional learning models. Empirical findings are discussed in section $6 ; 6.1$ examines the effect of observed mortgage rate drops and highlights the model's ability to capture much of the observed experience in the US housing market post-2000, while 6.2 shows the model's performance in attempting to match business cycle moments of the US housing market.

\section{Background \& Related Literature}

\section{$2.1 \quad$ Background}

Across almost all of the major urban centers in the United States price-rent ratios rose between 20 and 70 percent in the 10 years leading up to the market crash. The experience in US housing is widely seen as being central to the subsequent crisis in global financial markets and the ensuing recession. Housing wealth, about 80 percent of which is encompassed by the stock of owner-occupied homes, accounts for

half of household net worth in the United States (Iacoviello (2011)) and residential investment has been a relatively large component of US GDP growth over the past 30 years (Wheaton and Nechayev (2010)). In 
spite of the prevalence and importance of housing booms, data on housing market fundamentals typically doesn't display large volatilities. Consequently, standard frameworks struggle to explain large and persistent movements in house prices $^{1}$, suggesting a role for an expectations-based explanation. The overweighting of recently observed information in the formation of beliefs, particularly beliefs about long horizon events, is documented in many settings ${ }^{2}$. An implication of such extrapolative behavior when applied to beliefs about price movements is that agents tend to underpredict price growth during inflationary periods and overpredict growth during deflations.

Figure 1: Home Price Index Futures

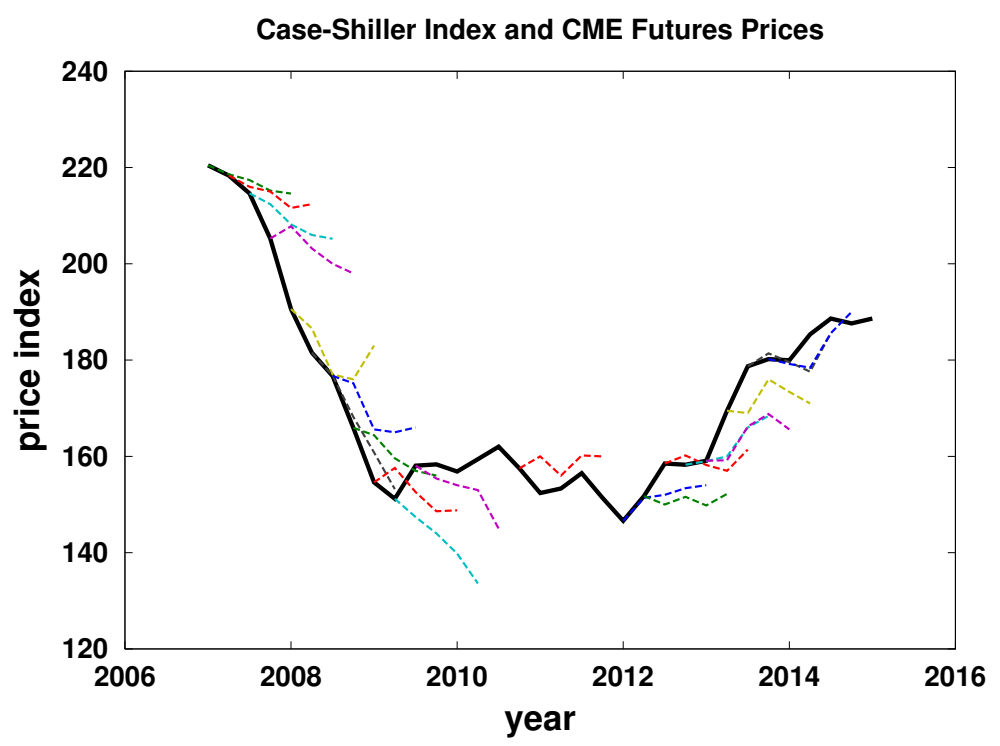

Figure 1 plots the 10-city composite of the Case-Shiller Home Price Index together with the prices of futures contracts that trade on this index on the Chicago Mercantile Exchange ${ }^{3}$. The futures contracts provide a proxy for market expectations about future house prices, and they bear the evidence of extrapolative expectations. Following the crest in US house prices in 2006, forecasts substantially overpredicted the realized path of house prices for the best part of two years. After beliefs about future growth adjusted in late 2007, the forecasted series missed the turning point at the bottom of the market in 2009 and persis-

\footnotetext{
${ }^{1}$ Literature has arisen as a result that attempts to explain housing booms as arising from a variety of different and often conflicting mechanisms, including: varying supply-side constraints (see Gleaser et al. (2008), Bulusu, Duarte, and VergagaAlert (2013), Kiyotaki, Michaelides, and NIkolov (2011)), demand-side factors such as changes in credit conditions (Chu (2014), Favilukis, Ludvigson, and Nieuwerburgh (2010)), income instability (Nakajima (2011), Pastor and Veronesi (2006)), and social interaction mechanisms (Burnside, Eichenbaum, and Rebelo (2011)). Also see Justiniano, Primiceri, and Tambalotti (2015) for further discussion

${ }^{2}$ See Adam and Marcet (2011), Eusepi and Preston (2011), Glaeser, Gyourko, and Saiz (2008) for discussion.

${ }^{3}$ Note a version of this figure appears in Gelain and Lansing (2013).
} 
tently underpredicted prices as inflation began in 2012. Similar evidence is documented in Case and Shiller (2003) and Piazzesi and Schneider (2009), who estimate household beliefs about price increases and find increasing levels of optimism throughout the run-up in house prices in the mid 2000s. ${ }^{4}$

This evidence suggests a potential mechanism for resolving the observed boom in prices with the relative lack of variation in market fundamentals. If agents' beliefs about future events, particularly in the long-run, are sufficiently responsive to shocks, booms may arise as self-confirming events: shocks to prices may shift the distribution of expected prices - and therefore expected capital gains, expected default rates, etc... enough to generate large increases in demand and therefore subsequent price growth. In formulating a learning model in which boundedly rational agents recursively update beliefs about the process for house prices this paper captures precisely these kind of dynamics.

Figure 2: House Prices \& Household Borrowing

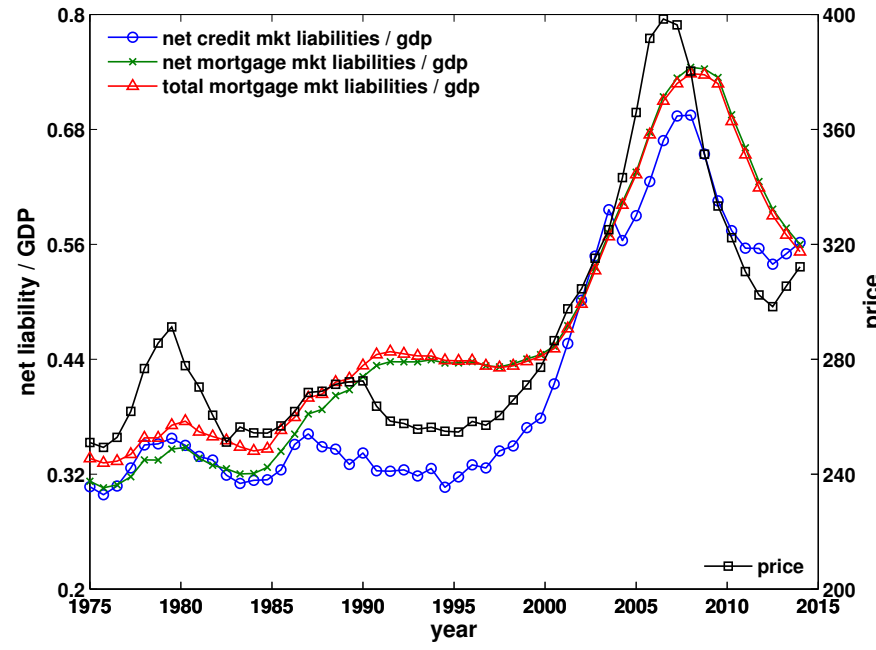

(a) US House Prices \& Credit Market Liabilities

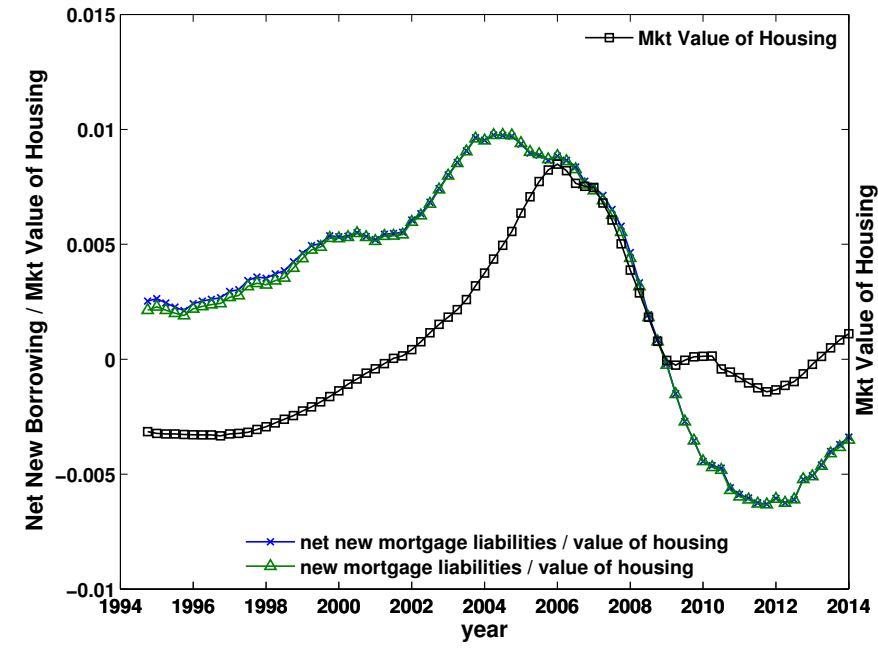

(b) Value of Housing \& Mortgage Liabilities

A key feature of the US house price boom was the large increase in credit provided to households. The left hand panel in figure 2 plots the All-Transaction House Price index from the Federal Housing Finance Agency together which three measures of net household liabilities as a fraction of GDP. The right hand panel shows net new borrowing by US households as a fraction of the market value of housing stock. As can be seen, the data reveals close comovement between prices and household credit during the late 1990s and early-mid 2000s. It seems reasonable, then, that a story of price booms in US housing markets should

\footnotetext{
${ }^{4}$ Gelain and Lansing (2013)
} 
speak to this phenomenon. Under the learning framework developed in this paper, a simple contracting mechanism between households and lenders endogenously generates substantial comovement in house prices and household leverage ${ }^{5}$. This is a result of the sensitivity of credit supply to subjective beliefs. Shifts in the distribution of expected price growth cause lenders to significantly liberalize lending conditions to households, driving inflation in house prices and subsequent shifts in lenders' beliefs.

\subsection{Related Literature}

This work follows from a wide literature that models learning behavior of economic agents so as to amplify and propagate shocks in macro models. In such frameworks agents are assumed to be uninformed about some process or set of processes and hence hold subjective beliefs about their true law of motion. These beliefs are updated over time to account for new information via a learning rule such as Bayesian updating, least squares updating, or constant gain learning (under such an updating rule agents place a constant weight, called a gain, on new information). Typically, agents perceive that temporary shocks have long run effects through their influence on learned beliefs. Much of the initial interest in this work arose in the monetary policy and business cycle literature.

The ability of learning mechanisms to generate improved volatilities and comovements in macroeconomic environments has been mixed ${ }^{6}$. The range of results found in this literature can in part be accounted for by the effect different learning mechanisms have on the microfoundations of agents' decision problems. Preston (2005) argued that researchers implicitly impose an inconsistency upon agents' beliefs when assuming them to be uninformed about the future evolution of their own choice variables, an assumption that is common in the learning literature. When agents are uninformed about the true law of motion of some variable(s) in learning models, they forecast future values of these variables using a perceived law of motion that they have estimated from previously observed data. Hence, if uninformed about the law of motion of one of their own control variables, the agent's forecasts of this object are not constrained to be consistent with what optimal choices would be given its beliefs about the evolution of other variables in the model. Suppose, for example, that an agent is uninformed about the true process governing investment. In a learning framework, forecasted investment would then be given by the expected value of an estimated process for investment

\footnotetext{
${ }^{5}$ Box \& Mendoza (2014) study the effect of credit market liberalizations in a learning framework. The authors are able to capture significant growth in land prices, however credit market liberalizations are exogenously imposed and the model does not allow for feedback between agents' exogenous variables and beliefs.

${ }^{6}$ See Williams (2003), Carceles-Poveda and Giannitsarou (2008), Huang, Liu, and Zha (2009), and Milani (2007).
} 
and not by the expected optimal response of investment to prices and exogenous shocks. Such models therefore implicitly assume that agents are either uninformed about their decision problem in the future or that agents predict they will be making suboptimal decisions in the future. ${ }^{7}$

This work is extended by Adam and Marcet (2011) who formalize the concept of internal rationality. This stipulates that agents with subjective beliefs should make choices that are everywhere optimal conditional on these beliefs (ie. on and off the equilibrium path). In restricting subjective beliefs to the space of prices observed in the housing market the model formulated in this paper builds upon this work. There is growing evidence that such frameworks can improve the internal propagation mechanisms of models. Eusepi and Preston (2011) consider a real business cycle environment where agents are restricted to learning the parameters of wage and capital return functions via constant gain learning. The specification allows the consumption-saving decisions of households to be a discounted sum of subjective wage and rental rate forecasts. Relative to rational expectations the persistence of shocks and overall volatilities are substantially increased. Similar results are found in Branch and McGough (2011), while Sinha (2011) suggests that such learning specifications can improve the performance of business cycle models in matching financial moments $^{8} \cdot 9$

Asset pricing models with internally rational learning have achieved some success in explaining the observed volatility and persistence in asset prices (most notably stock prices and house prices) over the business cycle, however this research has thus far failed to provide a convincing explanation of price booms. Adam, Beutel, and Marcet (2014) propose a learning framework in which boundedly rational agents believe stock price growth to be governed by a simple linear hidden Markov model. A similar model is examined by Adam and Marcet (2010) with agents that are assumed to be uninformed about the evolution of stock returns instead of price growth. Both frameworks struggle to endogenously generate sequences of beliefs sufficient to yield price booms in general equilibrium settings.

Adam, Kuang, and Marcet (2011) implement a learning model, similar in spirit to that found in Adam, Beutel, and Marcet (2014), to try to explain joint house price-currentaccount movements in the G7 over the 2000s. The authors find that reductions in interest rates in the early 2000s can generate substantial

\footnotetext{
${ }^{7}$ Marshall and Shea (2013) provide an example of a learning model in housing where households are assumed to be uninformed about the evolution of their own consumption.

${ }^{8}$ Similar frameworks can be found in Adam, Marcet, and Nicolini (2013), Branch (2014), and Williams (2003).

${ }^{9}$ Note that a question that emerges from the initial learning literature in business cycle models is whether canonical macro models converge to rational expectations dynamics under learning. For a discussion of these issues see Evans and Honkapohja (2001), as well as Cellarier (2006), Cellarier (2008), Cho, Williams, and Sargent (2002), Evans and Honkapohja (2003), Ellison \& Pearlman (2011), McCallum (2007), Williams (2003), and Zhang (2012).
} 
increases in house prices as households become increasingly optimistic about price appreciation, however the result is highly sensitive to the initial conditions of beliefs and price growth at the time shocks hit. Similar models are formulated by Gelain and Lansing (2013) and Granziera and Kozicki (2012). This paper is also closely related to Kuang (2014) who considers a Kiyotaki and More (1997) environment with learning. Internally-rational agents in the model form beliefs about the joint law of motion for collateral prices and collateral stock. The author shows that the specified process of expectation formation can generate boombust cycles in prices and credit. This paper follows from Kuang (2014) in considering credit constraints to be an important channel through which learning can operate. This paper goes further, however, in considering a role for internal rationality in the determination of loan-to-value ratios. It shows that under such conditions boom-bust cycles can be obtained even with the simple models of expectation formation found in Adam, Kuang, and Marcet (2011), Gelain and Lansing (2013), and Granziera and Kozicki (2012). The environment specified here also allows for belief heterogeneity between borrowers and lenders.

Boz and Mendoza (2014) argue that credit market liberalizations in the late 1990s lie at the root of the US housing boom. The authors propose a learning framework in which agents learn a two-state Markovswitching model for collateral constraints, however the model cannot explain the majority of the growth in US house prices. ${ }^{10}$

This paper also contributes to a literature which considers the role of bounded rationality in driving the credit supply choices of financial institutions. Luzzetti and Neumuller (2015) argue that the dynamics of household debt and bankruptcy can in part be explained when lenders learn the riskiness of the financial environment in which they operate. Similarly, Pancrazi and Pietrunti (2014) consider the role that boundedly-rational beliefs about prices on the part of lenders can play in determining debt and home equity extraction.

\footnotetext{
${ }^{10}$ Many of the papers in the learning literature make stronger assumptions about agents' information structure. Gelain and Lansing (2013) study the behavior of US house prices under a form of learning where households make forecasts of a composite variable which is composed of price-rent ratios and consumption growth. Williams (2012) considers a model where agents learn the mean and standard deviation of stock returns. The model includes an occasionally-binding borrowing constraint about which the agent is uninformed and which it does not internalize in its decision problem. Branch, Petrosky-Nadeau, and Rocheteau (2014) examine US housing using a learning model with search and matching frictions in employment. Agents in the model believe that price growth will always exceed the level of growth extrapolated off of recent data.
} 


\section{A Model With Learning}

The housing market is modelled as an open economy environment. The key interactions in the model involve households who purchase and consume housing stock, and mortgage lenders who supply households with credit in return for claims on their housing. Housing stock is treated as an asset which, in addition to providing households with a source of capital gains, yields a flow of housing services and can be posted as collateral when borrowing. Household borrowing is subject to default. The paper abstracts from modelling strategic behavior in the household's default choice. While there is a rich literature that seeks to model the decision problem facing households when defaulting on residential mortgages, these issues are not central to the mechanism considered in the paper. The default choice is modelled to reflect observed default patterns in the data. Lenders are assumed to have access to an outside source of funds (ie. international financial markets) and are owned by agents outside the housing market.

In modelling the lender's problem the paper does not seek to provide a complete description of mortgage financing. Instead, the model provides a stylized contracting problem between lenders and households in order to capture observed properties of mortgage default as well as measured correlations between default rates, price growth, and household leverage. Lenders set their supply of credit in response to expected default rates and the value of their collateral claims in the event of default. Household demand is driven by expected capital gains, expected default rates, and their credit constraint.

All agents are assumed to be uninformed about the determination of house prices, and therefore hold subjective beliefs about the evolution of these prices in the economy. Beliefs are homogeneous across lenders and households, and are updated continuously to account for new information. Stationary Bayesian updating of beliefs implies that learning follows the well-known constant gain algorithm. Expectations about price growth at long horizons heavily weight recent price observations. Importantly, the information structure respects the international rationality of agents' decision problem. Household and lender choices are optimal responses to their subjective beliefs.

\subsection{Household Problem}

An individual household has preferences over consumption and housing services given by

$$
\mathbb{E}_{0}^{\mathcal{P}} \sum_{t=0}^{\infty} \beta^{t} u\left(c_{t}, h_{t}\right), \text { where } u\left(c_{t}, h_{t}\right)=c_{t}^{\gamma_{c}} h_{t}^{1-\gamma_{c}}
$$


where $\mathcal{P}$ denotes the household's subjective beliefs. The household receives an exogenous endowment $y_{t}$ each period out of which it can accumulate housing stock $h_{t}$ and purchase consumption goods (the numeraire in the economy). Housing stock has a price $q_{t}$ and depreciates at the rate $\delta_{h}$. The household also has access to a technology that allows it to convert consumption goods into non-housing capital one-for-one. Capital can be rented to builders, who are owned by the household, at a price $p_{t}$ and depreciates fully after one period. The household can also borrow from a credit supplier at a risk-free rate $R_{t}$ by posting its housing stock as collateral. All debt contracts are one period in length. The household's borrowing is limited by a collateral constraint

$$
R_{t} b_{t} \leq \theta_{t} \mathbb{E}_{t}^{\mathcal{P}} q_{t+1} h_{t}
$$

which is assumed to bind each period. The flow budget constraint is given by

$$
c_{t}+q_{t}\left(h_{t}-\left(1-\delta_{h}\right) h_{t-1}\right)+R_{t-1} b_{t-1}+k_{t}=y_{t}+b_{t}+p_{t} k_{t-1}+\Pi_{t}
$$

Where $\Pi_{t}$ denotes profits earned by builders. At the beginning of each period the household is able to decide whether or not it wants to default on its debt repayment $R_{t-1} b_{t-1}$. If it chooses not to repay then the lender confiscates the household's housing stock $\left(1-\delta_{h}\right) h_{t-1}$. The model abstracts from considerations of strategic default. Instead, households default so as to minimize their per-period repayment. However this process is subject to an idiosyncratic shock $\zeta$, such that the household chooses to default if

$$
\left(1-\delta_{h}\right) q_{t} h_{t-1} \leq \zeta_{t} R_{t-1} b_{t-1}, \quad \log \zeta_{t} \sim N\left(\log \bar{\zeta}, \sigma_{\zeta}^{2}\right)
$$

The shock $\zeta$ can be thought of as capturing differences in liquidity across households. This formulation allows the model to reflect the observed fact that only a subset of households who go into negative equity end up having their mortgages foreclosed. It is important to be clear about the timing of the default decision. Households make their default choice before chosing consumption and housing demand in a given period. Moreover, defaulting households are not subsequently excluded from housing or debt markets. As a result, households are not constrained to consume zero housing in the periods in which they default.

The household side of the model is completed by outlining the supply of new housing stock. Builders construct new housing stock from the physical capital they rent from households, according to a production 
function $h_{s}=f(k)=A k^{\alpha}$. Profits earned by builders are returned to the households. The builders' profit maximization problem is given by

$$
\max _{\tilde{k}}\left\{\Pi\left(q_{t}, p_{t}, \tilde{k}\right)=q_{t} A \tilde{k}^{\alpha}-p_{t} \tilde{k}\right\} \Longrightarrow p_{t}=\alpha q_{t} A \tilde{k}_{t}^{\alpha-1}
$$

\subsection{Lender Problem}

The representative lender chooses the amount of credit to supply to the household at the note rate $R_{t}$. The lender is assumed to have access to an outside source of funds (ie. international financial markets) from which it can borrow. In the event of default, a household's stock of housing is transferred to the lender. The lender can recoup the value of the collateral in the housing market, however it faces delay in doing so. In particular, the lender can only sell a unit of the foreclosed housing stock in its possession with probability $\mu$ each period. This assumption captures the presence of delay in the foreclosure process and allows the lender's choice to depend on its beliefs about long-horizon events. The lender's valuation of housing is also subject to a stochastic markdown, $\phi_{t}{ }^{11}$. $\phi_{t}$ is assumed to follow a random walk in logs (which bounds $\left.\phi_{t}>0\right)$

$$
\log \phi_{t}=\log \phi_{t-1}+\epsilon_{t}^{d}
$$

which is known to the lender. The calibration of this process allows the model to match observed correlations between lagged house prices and household leverage. The lender's profits are given by

$$
\begin{aligned}
\Pi^{L} \mid h_{t}, \mathcal{P}= & -\tilde{b}_{t}+\beta(1-\operatorname{Pr}(\text { default } \mid \mathcal{P})) \cdot R_{t} \tilde{b}_{t}+\ldots \\
& \operatorname{Pr}(\text { default } \mid \mathcal{P}) \cdot\left[\sum_{j=1}^{\infty} \beta^{j}\left(1-\delta_{h}\right)^{j} \mu(1-\mu)^{j-1} \mathbb{E}_{t}^{\mathcal{P}}\left(\phi_{t+j} q_{t+j}\right) h_{t}\right]
\end{aligned}
$$

where $\mathcal{P}$ denotes the lender's beliefs about future prices. Normalizing $\Pi^{L}$ by the value of household's housing stock, the profit maximization problem can be written

$$
\max _{\theta}\left\{\begin{array}{r}
-\frac{\theta}{R} \cdot \mathbb{E}_{t}^{\mathcal{P}}\left(\frac{q_{t+1}}{q_{t}}\right)+\beta(1-\operatorname{Pr}(\text { default } \mid \mathcal{P})) \cdot \theta \cdot \mathbb{E}_{t}^{\mathcal{P}}\left(\frac{q_{t+1}}{q_{t}}\right)+\ldots \\
\operatorname{Pr}(\text { default } \mid \mathcal{P}) \cdot\left[\sum_{j=1}^{\infty} \beta^{j}\left(1-\delta_{h}\right)^{j} \mu(1-\mu)^{j-1} \mathbb{E}_{t}^{\mathcal{P}}\left(\phi_{t+j} \frac{q_{t+j}}{q_{t}}\right)\right]
\end{array}\right\}
$$

\footnotetext{
${ }^{11} \phi_{t}$ can be thought of as capturing non-monetary costs/benefits to liquidating foreclosed housing in a given period (ie. a liquidity value).
} 


$$
\Longrightarrow \theta^{*}=\theta\left(m_{t}\right)
$$

Where $\theta$ is the value of the debt repayment $R_{t} b_{t}$ as a fraction of the expected value of the household's housing stock, $\mathbb{E}^{\mathcal{P}}\left(q_{t+1} h_{t}\right)$. In other words, conditional on its observation of $\left(q_{t}, h_{t}\right)$ and its beliefs $\mathcal{P}$, the lender's choice of credit supply $\tilde{b}$ is equivalent to determining the credit constraint that the household faces in $(2)^{12}$. The lender's choice of $\theta_{t}$ implies that the perceived probability of default is given by

$$
\operatorname{Pr}(\text { default } \mid \mathcal{P})=\operatorname{Pr}\left[\log \left(\frac{q_{t+1}}{q_{t}}\right)-\log \left(\zeta_{t+1}\right) \leq \log \left(\frac{\theta_{t}}{1-\delta_{h}}\right)+\log \left(\mathbb{E}_{t}^{\mathcal{P}}\left(\frac{q_{t+1}}{q_{t}}\right)\right)\right]
$$

The lender's credit supply choice is determined by the probability of default and the value of its claims to the collateral in the event of default. As can be seen in (8), delay in the sale of foreclosure inventory implies that the value of the lender's claim to the housing stock depends on long-run forecasts of price growth ${ }^{13}$. This introduces a degree of convexity in the supply of credit with respect to the belief $m_{t}$.

The contracting problem in the model is intentionally quite stylized, as the determination of mortgage structure is not the focus of this paper. The model could be augmented to allow the mortgage rate or additionally, in a substantially more complex setting, the term structure of the mortgage to be endogenized as part of the lender's choice problem. In such a case the essential mechanism through which lenders and households interact is the same. Expectations of future house price growth increases the willingness of the lender to carry the risk of lending, while liberalizations in the supply of credit increase the demand for housing on the part of households.

\subsection{Learning \& Subjective Beliefs}

The key informational assumption in the model is that each agent is only aware of their own decision problem. Their information set does not contain the decision problem of any other agent in the economy. An immediate consequence of this is that agents do not know the correct mapping between the state variables of the economy and the prices that they observe, as these are equilibrium outcomes and therefore functions of other agents' choices. Agents do know their own choice problem and so are capable making decisions which are optimal conditional on their beliefs (to be precise, their beliefs about the distribution of

\footnotetext{
${ }^{12}$ As the household's problem is calibrated to ensure that (2) binds in each period, the household will always be willing to accept this contract.

${ }^{13}$ Alternatively, this could be achieved through the presence of a foreclosure cost, however the assumed cost function would need to be a function of expected forward prices, which is not intuitive.
} 
variables outside of their decision set, $\mathcal{P}^{i}$ ). In this respect agent behavior satisfies the standard of Internal Rationality (Adam and Marcet (2011)). The restriction on their information implies, however, that these beliefs will not include the objective distribution of prices. In order to be able to make choices agents hold subjective beliefs about house prices. These beliefs are assumed to be homogeneous amongst all agents in the economy and are extrapolated from observed prices through learning. As a result, the model allows for feedback between subjective beliefs and equilibrium prices.

As has been widely studied in the learning literature, simple rule-of-thumb updating rules can capture the property that long-horizon price forecasts heavily weight recent price data, consistent with the evidence discussed in sections 1 and 2. Such updating rules arise endogenously from Bayesian learning of parsimonious hidden state models. Agents in the model perceive that prices are generated by the following data generating process (DGP)

$$
\begin{aligned}
& \ln \frac{q_{t}}{q_{t-1}}=\ln \omega_{t}+\epsilon_{t}^{q} \\
& \ln \omega_{t}=\ln \omega_{t-1}+\epsilon_{t}^{\omega}
\end{aligned}\left(\begin{array}{c}
\epsilon_{t}^{q} \\
\epsilon_{t}^{\omega}
\end{array}\right) \stackrel{i i d}{\sim} N\left(\begin{array}{l}
0 \\
0
\end{array},\left(\begin{array}{cc}
\sigma_{q}^{2} & 0 \\
0 & \sigma_{\omega}^{2}
\end{array}\right)\right)
$$

where the persistent component of price growth, $\log \omega_{t}$, is a hidden state variable. Agents observe the realization of $\ln \frac{q_{t}}{q_{t-1}}$ and learn by updating beliefs about the distribution of $\ln \omega_{t}$. The choice of perceived DGP follows a number of papers in the asset pricing learning literature, including Adam, Kuang, and Marcet (2011) and Adam, Beutel, and Marcet (2014). Optimal updating of (11) implies patterns of forecast errors in prices consistent the evidence discussed in section 2.1 .

Under stationary Bayesian learning, an agent's posterior beliefs about $\ln \omega_{t}$ are given by

$$
\begin{gathered}
\ln \omega_{t} \sim \mathrm{N}\left(\ln m_{t}, \sigma_{0}\left(\sigma_{q}, \sigma_{\omega}\right)^{2}\right) \\
\sigma_{0}^{2}=\frac{-\sigma_{\omega}^{2}+\sqrt{\sigma_{\omega}^{4}+4 \sigma_{q}^{2} \sigma_{\omega}^{2}}}{2}
\end{gathered}
$$

The stationary Kalman filtering equations imply the constant gain algorithm for updating beliefs about the posterior mean, $\ln m_{t}$

$$
\begin{gathered}
\ln m_{t}=\ln m_{t-1}+g\left(\sigma_{q}, \sigma_{\omega}\right) \cdot\left(\ln \frac{q_{t}}{q_{t-1}}-\ln m_{t-1}\right) \\
g\left(\sigma_{q}, \sigma_{\omega}\right)=\frac{\sigma_{0}\left(\sigma_{q}, \sigma_{\omega}\right)^{2}}{\sigma_{q}^{2}}
\end{gathered}
$$


Under constant gain updating (14), posterior beliefs will be a weighted average of past price growth observations. The gain parameter $g$, which controls the weight agents place on new price data when forming beliefs, is equivalent to the inverse of the rate at which old observations are discounted over time ${ }^{14}$.

Given this belief structure, $\mathbb{E}_{t}^{\mathcal{P}}\left(q_{t+j} / q_{t}\right)$ in $(8)$ can be written as

$$
\mathbb{E}_{t}^{\mathcal{P}}\left(\frac{q_{t+j}}{q_{t}}\right)=\exp \left(j \log \left(m_{t}\right)+\frac{1}{2} j^{2} \sigma_{0}^{2}\right) \cdot \exp \left(\frac{1}{2} j \sigma_{q}^{2}\right) \cdot \exp \left(\frac{1}{2} \sigma_{\omega}^{2} \sum_{s=1}^{j} s^{2}\right)
$$

While the representative lender doesn't observe the households' decision problem in full, it is aware of the liquidity shock, $\zeta_{t}$, and as a result can infer a perceived default pobability from its beliefs about prices. A shift in beliefs $m_{t}$ influences the lenders' supply of credit via its effect on perceived default probabilities and the expected values of the lenders' claims on housing

$$
m_{t} \uparrow \Longrightarrow\left\{\begin{array}{c}
P_{t}^{\mathcal{P}} \text { (Default) } \downarrow \\
\mathbb{E}_{t}^{\mathcal{P}}\left(\Pi_{t+1}^{\text {L, default }}\right) \uparrow
\end{array}\right\} \Longrightarrow \tilde{b}_{t}, \theta_{t} \uparrow
$$

The household's Euler equation for housing is given by

$$
q_{t}=\frac{u_{h}(t)}{u_{c}(t)}+\mathbb{E}_{t}^{\mathcal{P}}\left[\left(\beta(1-\delta) \cdot \frac{\lambda_{t+1}^{i}}{\lambda_{t}^{i}} \cdot \Gamma_{t+1}+\frac{\theta_{t}}{R}\right) \cdot q_{t+1}-\beta \theta_{t}\left(\mathbb{E}_{t}^{\mathcal{P}} q_{t+1}\right) \frac{\lambda_{t+1}^{i}}{\lambda_{t}^{i}} \Gamma_{t+1}\right]
$$

where $\Gamma_{t+1}=1-\operatorname{Pr}($ default $\mid \mathcal{P})$ in $(10)$. Increases in the economy-wide posterior mean of the permanent component of price growth, $\log m_{t}$, directly influence the households' housing demand via three complementary channels: (i) increasing expected capital gains on housing, (ii) increasing the supply of credit available to the households, and (iii) decreasing the households' expected default probability. As neither the lender nor the households understand the correct mapping between fundamentals and prices, it is assumed that neither agent is able to account for the effect of their actions on future beliefs. In other words, when forecasting future prices the agents also do not internalize the effect of future price movements on $m_{t}{ }^{15}$.

A few comments should be made at this point about the assumption that beliefs in the model are

\footnotetext{
${ }^{14}$ The constant gain makes this a model of perpetual learning. Even when the DGP (11) is correctly specified, discounting of past data implies that $m_{t}$ will not converge in levels. In this case, however, beliefs should be ergodically distributed around the rational expectations equilibrium when the gain is small (see Evans and Honkapohja (2001)).

${ }^{15}$ This is commonly referred to as the anticipated utility assumption (see Kreps (1998) and Sargent (1999)). In practice this assumption does not have a significant effect on the results presented in section 6 and is made for computational ease.
} 
homogeneous across all agents. Heterogeneity could be incorporated into the model in a number of different ways: (i) households and lenders could be assumed to have the same perceived data generating process for prices (11) but differ with respect to rate at which they discount the past (ie. $g$ varies between households and lenders), (ii) the perceived data generating process for prices could differ between households and lenders, or (iii) heterogeneity could be assumed in the beliefs amongst households and lenders. In the case of (i), the dynamics of the model would be equivalent to formulation considered here with a different overall gain. In the case of (ii), a general comment about the effect on the model's dynamics cannot be made, however the available evidence does not support the conclusion that financial institutions and households hold structurally different beliefs about house prices ${ }^{16}$. Finally, in the case of (iii), the model considered here abstracts from a transaction margin in housing and features an intentionally sparse contracting problem. This is done so as to retain a focus on aggregate price movements. As a consequence it is not a rich framework in which to consider heterogeneity in beliefs amongst households and lenders ${ }^{17}$.

\subsection{Equilibrium Under Learning}

The equilibrium concept of the model is an Internally Rational Expectations Equilibrium (IREE), formalized by Adam and Marcet (2011). An Internally Rational Expectations Equilibrium for this economy is characteized by:

1. A probability measure $\mathcal{P}^{i}$ representing an agent's beliefs over $\Omega_{s}$, where $\Omega_{s}$ denotes the space of realizations of variables exogenous to an agent.

2. A sequence of equilibrium prices $\left\{p_{t}^{*}, q_{t}^{*}\right\}_{t=0}^{\infty}$ where $p_{t}^{*}, q_{t}^{*}: \Omega_{S}^{t} \rightarrow R_{+}^{N} \forall t$. Markets clear for all $t$, all realizations in $\Omega_{S}$ almost surely in $\mathcal{P}^{i}$.

3. A sequence of choice functions $\left\{c_{i t}^{*}, h_{i t}^{*}, k_{i t}^{*}, b_{i t}^{*}, \tilde{k}_{i t}^{*}, \tilde{b}_{i t}^{*}, \tilde{h}_{i t}^{*}\right\}_{t=0}^{\infty}$ that maximize agent $i$ 's objective function conditional on $\mathcal{P}^{i}$. All agents $i=1, \ldots, I$ are internally rational.

A rational expectations equilibrium can be viewed as a being a special case of an IREE. In particular, a rational expectations equilibrium is an IREE in which subjective beliefs $\mathcal{P}^{i}$ coincide with the objective probability distribution. Under rational expectations agents infer the correct process for prices from their knowledge of the system. In the equilibrium considered here the agents' knowledge of the system is incomplete, hence their beliefs will not in general coincide with the objective distribution over outcomes external

\footnotetext{
${ }^{16}$ See Cheng, Raina, and Xiong (2012)

${ }^{17}$ Note, Burnside, Eichenbaum, and Rebelo (2011) consider a housing model with heterogeneity between households. Calibrating the distribution of prior beliefs across agents remains an empirical challenge in such frameworks, however.
} 
to their decision set. Nevertheless, the microfoundations of agents' choices are preserved as decisions are always optimal conditional on subjective beliefs.

The model is closed by specifying the market clearing condition for housing. The solution to the households' problem yields an aggregate housing demand function $h^{d}\left(h_{t-1}^{d}, k_{t-1}, b_{t-1}, q_{t}, m_{t}, \theta_{t}, y_{t} \mid \mathcal{P}\right)$. The market clearing price $q_{t}^{*}$ is determined by the identity

$$
h^{d}\left(h_{t-1}^{d}, k_{t-1}, b_{t-1}, q_{t}^{*}, m_{t}, \theta_{t}, y_{t} \mid \mathcal{P}\right)-\left(1-\delta_{h}\right)\left(1-D_{t}\right) h_{t-1}^{d}=A k_{t-1}^{\alpha}+\mu\left(1-\delta_{h}\right) \cdot\left(D_{t} h_{t-1}^{d}+F_{t-1}\right)
$$

where $D_{t}$ is the proportion of households who default in period $t$ and $F_{t-1}$ is the inventory of foreclosed housing that the lender holds at the end of period $t-1$. The left hand size of (18) denotes new purchases of housing after default choices are made. The amount of housing made available for sale is given by the sum of newly constructed housing and the proportion $\mu$ of the foreclosure stock the lender is able to liquidate. The law of motion for $F$ is given by

$$
F_{t}=(1-\mu)\left(1-\delta_{h}\right)\left(F_{t-1}+D_{t} h_{t-1}\right)
$$

The presence of default in the model implies that housing stock will be heterogeneous across households. Owing to the fact that per period utility in (1) is Cobb-Douglas, the household side of the model can nevertheless be aggregateed to a representative household structure with stochastic default (the representative households loses only a fraction of his/her housing stock each period as a result of default). The aggregation is shown in appendix B.

The household problem is solved via a form of parameterized expectations using spectral methods. The details of the solution method can be found in appendix C. The lender's decision rule is approximated by a simple interpolation of the solution to (8). Given these two approximations the market clearing prices can be solved for any state vector via (18).

\section{Calibration}

The complete set of calibration results can be found in table $1^{18}$. Exogenous variation in the model comes from the endowment process $y_{t}$ and mortgage rate $R_{t}$. The endowment is estimated as a log $\operatorname{AR}(1)$ process

\footnotetext{
${ }^{18}$ Appendix D lists the data sources used for this paper.
} 
using detrended wages and salaries compensation data from the Bureau of Economic Analysis (BEA) ${ }^{1920}$. The mortgage rate series is taken from Freddie Mac's 30-year fixed mortgage average for the United States. An Augmented Dickey-Fuller test on the series does not reject the hypothesis of a unit root, and the mortgage rate process is estimated as being a random walk in logs. ${ }^{21}$

The delay in liquidating foreclosed housing, $\mu$, is set so that foreclosure stock as a fraction of total housing in steady state equals its 1996 value in the National Delinquency Survey of the Mortgage Bankers Association. The determination of credit supply in the model implies a correlation between a weighted average of past prices $\left(m_{t}\right)$ and household leverage. The length and volatility of the lenders' markdown shock $\left\{\epsilon_{s}^{d}\right\}_{s=1}^{T}$ are chosen so as to match this correlation as measured from the data, as well as the level of loan-to-value (LTV) ratios on US mortgages. Using the Federal Housing Finance Agency's (FHFA) AllTransaction House Prices Series for the United States, a sequence $\hat{m}_{t}(g)$ is estimated using (14). Household leverage is measured using net mortgage liabilities from the Federal Reserve Financial Accounts as a fraction of the aggregate market value of non-farm residential homes, taken from Davis and Heathcote (2007). The level of the series is adjusted to match the mean LTV ratio on US mortgages in 1996 Q1, measured in the American Housing Survey (AHS). The parameters are set so that (i) the correlation between these two series matches the implied correlation of the lender's choice of $\theta_{t}$ with $m_{t}$ in the model, and (ii) steady state $\theta$ matches the LTV ratio in the US in 1996 Q1.

The parameters governing the liquidity shock, $\bar{\zeta}$ and $\sigma_{\zeta}$, in part control the level of default in the model as well as its volatility. The pair $\left(\bar{\zeta}, \sigma_{\zeta}\right)$ are set so that $(\mathrm{i})$ the level of default in steady state matches the aggregate delinquency rate on single-family residential mortgages in the US in 1996 Q1 (measured by the St. Louis Federal Reserve), and (ii) the elasticity of default with respect to $\theta$ matches an estimated elasticity of the delinquency rate with respect to household leverage from 1992 Q1 to 2014 Q1.

The gain parameter determines both the size and persistence of the response of beliefs to changes in prices. It is therefore key in governing the dynamics of the model. The beliefs are calibrated so as to match forecast errors taken from the data as follows. The perceived DGP for house price growth (11) implies the

\footnotetext{
${ }^{19}$ The wages and salaries data is detrended using a bandpass filter. An AR(1) process is specified to limit the number of state variables in the model for computational ease.

${ }^{20}$ The model presented in section 3 is a zero trend growth environment with a well-defined stationary steady state, hence the model is simulated with shocks to detrended incomes.

${ }^{21}$ When simulating the model, shocks to $y$ and $R$ are correlated. The correlation is estimated from measured shocks in the data.
} 
relationship

$$
\operatorname{Var}\left(\log \frac{q_{t}}{q_{t-1}}-\log \frac{q_{t-1}}{q_{t-2}}\right)=f\left(\sigma_{q}, \sigma_{\omega}\right)
$$

This identity, together with the identities (13) and (15) implies a relationship

$$
\sigma(g)=\left(\sigma_{0}(g), \sigma_{q}(g), \sigma_{\omega}(g)\right)
$$

Therefore, the choice of $g$ together with the variance in (20) implies the values of the prior variances $\sigma_{q}$ and $\sigma_{\omega}$. In order to choose $g$ the left hand side of (20) is measured from the FHFA house price series ${ }^{22}$ and the model is simulated over a grid of $g$ values (where for each $g$ the priors are set according to $\sigma(g)$ ) using shocks to $y_{t}$ and $R_{t}$ measured in the data. The chosen gain is that which minimizes the sum of squared errors between the vector of model-implied one-quarter-ahead forecast errors $\log \frac{q_{t}}{q_{t-1}}-\mathbb{E}_{t-1}^{\mathcal{P}} \log \frac{q_{t}}{q_{t-1}}$ and a data analog of this series. Forecast error data is constructed using the prices of futures contracts on the S\&P Case-Shiller home price index, which trade on the Chicago Mercantile Exchange. The futures prices can be thought of as a measure of the market's expectations about house prices ${ }^{23}$. The calibrated gain is 0.014. This value is slightly smaller than the quarterly-implied gain parameter estimated in Adam, Kuang, and Marcet (2011) and sits within the range of values typically found in the learning literature ${ }^{24}$.

The parameter $\gamma_{c}$ in the utility function is equal to the consumption share of disposable income. This is set to 0.558 using BEA data on personal consumption expenditures ${ }^{25}$. The elasticity of housing supply in the model is given by $\alpha /(1-\alpha)$. The parameter $\alpha$ is set using Saiz (2010), who provides estimates of local-level supply elasticities computed using data on land availability at the MSA level. The discount factor $\beta$ is set to 0.96 so that the borrowing constraint binds in each period. In order to ensure a stable solution to the household's problem a compromise has to be made in the calibration of the depreciation rate, $\delta_{h}$, which is set to the relatively high value of 0.06 . It should be noted, however, that this compromise serves to dampen rather than accentuate price volatility during model simulations.

\footnotetext{
${ }^{22}$ The level of the house price series is set using the Census Bureau's 2005 American Community Survey.

${ }^{23}$ The futures contracts use price movements in the 10-city composite of the S\&P Case-Shiller index, which covers the following housing markets in the United States: Boston, Chicago, Denver, Las Vegas, Los Angeles, Miami, New York, San Diego, San Francisco, and Washington, DC. The data series for forecast errors begins in 2007 Q1.

${ }^{24}$ See Adam, Kuang, and Marcet (2011). It should be noted that the size of gains found in the learning literature vary with respect to the setting concerned. One should not necessarily expect estimated/calibrated gains to be the same in models where agents learn about asset prices as in models where they learn about economy wide output or wages for example, as it is reasonable to assume that agents' information about these objects differ.

${ }^{25} \gamma_{c}$ is set equal to the 1999-2012 mean of the sum of the GDP shares for personal consumption expenditures on durables, nondurables, and services, minus the GDP share of personal consumption expenditures on housing services (imputed rental of owner-occupied non-farm housing).
} 
Table 1: Calibrated Parameter Values

\begin{tabular}{cl|c}
\hline \hline \multicolumn{1}{c}{ Parameter } & Value \\
\hline \multicolumn{2}{c}{ discount factor } & 0.96 \\
$\beta$ & depreciation of housing & 0.06 \\
$\delta_{h}$ & consumption share of income & 0.558 \\
$\gamma_{c}$ & curvature on housing production & 0.0172 \\
$\alpha$ & steady state $\theta$ & 0.834 \\
$\theta_{s s}$ & prob. of lender selling housing unit & 0.69 \\
$\mu$ & persistence in $y_{t}$ & 0.948 \\
$\rho_{y}$ & steady state default rate & $2.25 \%$ \\
$d e f_{s s}$ & 0.124 \\
$\bar{\zeta}$ & mean liquidity shock & 1.155 \\
$\sigma_{\zeta}$ & std. dev of log liquidity shock & $7.957 \times 10^{-4}$ \\
$\sigma_{0}$ & posterior std. dev & $9.482 \times 10^{-4}$ \\
$\sigma_{w}$ & priors std. dev. of $\epsilon_{t}^{\omega}$ & $6.725 \times 10^{-2}$ \\
$\sigma_{q}$ & priors std. dev. of $\epsilon_{t}^{q}$ & 0.026 \\
$\sigma_{d}$ & std. dev. of $\epsilon_{t}^{d}$ & 0.014 \\
$g$ & gain parameter & \\
& & \\
\hline \hline
\end{tabular}

\section{$5 \quad$ Analytic Results}

When both households and the suppliers of credit use subjective beliefs to forecast price movements, learning creates complementarities between the two sides of the market. This departure from standard demand-side learning frameworks bolsters the internal propagation mechanisms of the model. In order to demonstrate the difficulty in generating price booms with demand-side learning, consider the model outlined in Section 3 without the lender's problem discussed in 3.2. Such a model is similar to the demand-side learning models of Adam, Kuang, and Marcet (2011); Adam, Beutel, and Marcet (2014); and Gelain and Lansing (2013) ${ }^{26}$. Self-confirming deviations in prices occur through a simple feedback mechanism ${ }^{27}$

$$
q_{t} \uparrow \Longrightarrow m_{t} \uparrow \Longrightarrow \mathbb{E}_{t}^{\mathcal{P}}[\text { Capital Gain }] \Longrightarrow q_{t+1} \uparrow \Longrightarrow m_{t+1} \uparrow
$$

\footnotetext{
${ }^{26}$ Such a setting can also be related to learning frameworks used to explain stock price volatilities. Winkler (2015) considers an environment in which both investors and firms learn the stock price of the firm. Investors are concerned about capital gains on their investments while firms have a debt financing constraint that depends upon their market value. This can be considered a decentralization of the setting considered here.

${ }^{27}$ Note that shifts in expected capital gains operate on the household choice through two channels: (i) through changes in the expected resale value of housing stock, and (ii) through their effect on the household's credit constraint.
} 
In order to generate large and persistent price growth without relying upon a rich set of shocks to fundamentals, such a mechanism requires subjective beliefs to exhibit two properties. First, beliefs must be sufficiently responsive to price changes that the resulting response of demand drives subsequent price increases. Second, the belief process $m_{t}$ itself must be highly persistent. The trade-off between the two can be illustrated by deriving a law of motion for $m_{t}$. Writing the household's Euler equation (17) in simplified form

$$
q_{t}=\Theta_{t}+q_{t} m_{t} \mathbb{E}_{t}^{\mathcal{P}}\left[\rho_{t+1}\right] \quad{ }^{28}
$$

This implies

$$
\begin{aligned}
q_{t} & =\frac{\Theta_{t}}{1-m_{t} \mathbb{E}_{t}^{\mathcal{P}}\left[\rho_{t+1}\right]} \\
\Longrightarrow \log \left(\frac{q_{t}}{q_{t-1}}\right) & =\log \left(\frac{\Theta_{t}}{\Theta_{t-1}}\right)+\log \left(\frac{1-m_{t-1} \mathbb{E}_{t-1}^{\mathcal{P}}\left[\rho_{t}\right]}{1-m_{t} \mathbb{E}_{t}^{\mathcal{P}}\left[\rho_{t+1}\right]}\right)
\end{aligned}
$$

Substituting (24) into (14) yields

$$
\log m_{t}=(1-g) \log m_{t-1}+g \log \left(\frac{\Theta_{t}}{\Theta_{t-1}}\right)+g \log \left(\frac{1-m_{t-1} \mathbb{E}_{t-1}^{\mathcal{P}}\left[\rho_{t}\right]}{1-m_{t} \mathbb{E}_{t}^{\mathcal{P}}\left[\rho_{t+1}\right]}\right)
$$

linearizing this equation yields:

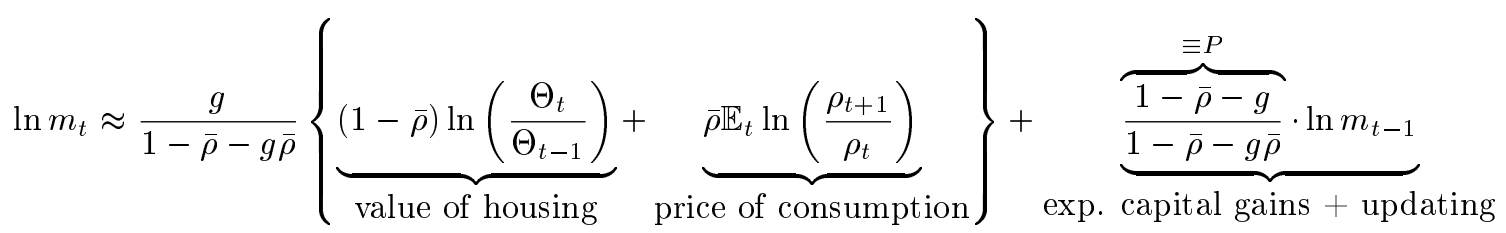

Note that the persistence parameter $P$ is downward sloping with respect to $g$

$$
\frac{d P}{d g}=\frac{-\bar{\rho}^{2}+2 \bar{\rho}-1}{(1-\bar{\rho}-g \bar{\rho})^{2}} \begin{cases}<0 & \text { if } \bar{\rho} \neq 1 \\ =0 & \text { else }\end{cases}
$$

\footnotetext{
${ }^{28}$ Where

$$
\begin{aligned}
\Theta_{t} & =u_{h}(t) / u_{c}(t) \\
\rho_{t+1} & =\left(\beta(1-\delta) \cdot \frac{\lambda_{t+1}^{i}}{\lambda_{t}^{i}} \cdot \Gamma_{t+1}+\frac{\theta_{t}}{R}\right) \cdot \Sigma_{t+1}-\beta \theta_{t}\left(\mathbb{E}_{t}^{\mathcal{P}} \Sigma_{t+1}\right) \frac{\lambda_{t+1}^{i}}{\lambda_{t}^{i}} \Gamma_{t+1} \\
\Sigma_{t+1} & =\exp \left(\sigma_{0} \epsilon_{t+1}+\epsilon_{t+1}^{q}+\epsilon_{t+1}^{\omega}\right) \quad \epsilon_{t} \sim N(0,1)
\end{aligned}
$$
}


Figure 3: Response to Endowment Shock, Demand-Side Learning

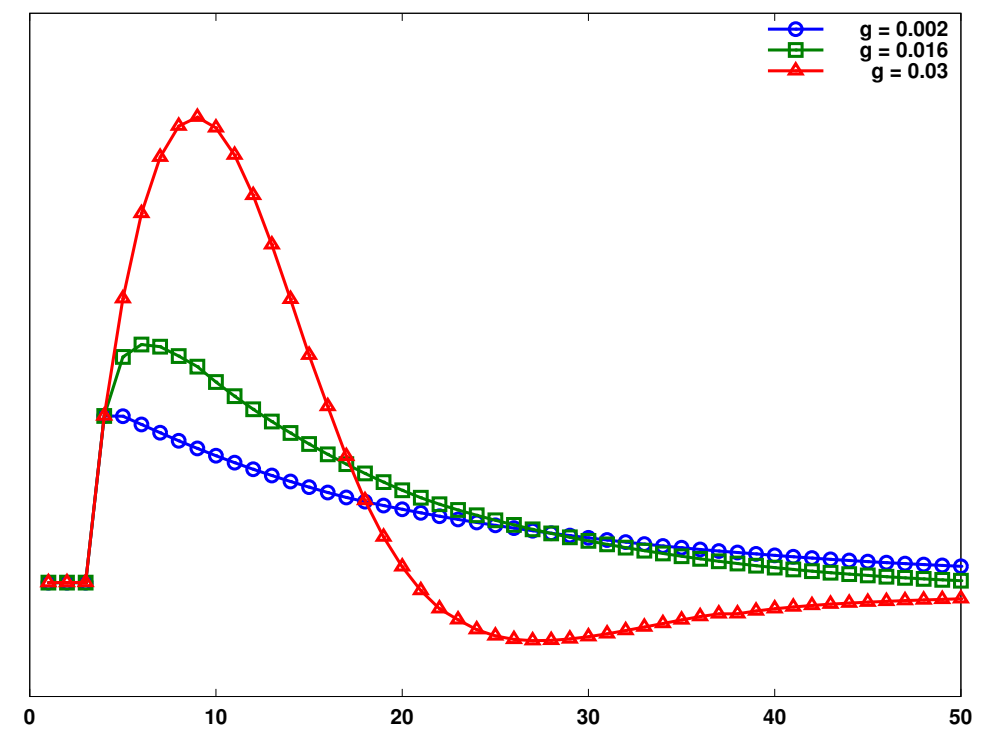

The law of motion (26) makes clear that in the absence of highly persistent shocks or strong internal propagation mechanisms in the model, persistent growth in $m_{t}$ requires a relatively large value for $P$. Given (27), this can be achieved be lowering the value of the gain parameter. The gain parameter, however, determines the weight that agents place on new information when updating beliefs. Hence, a reduction in $g$ diminishes the responsiveness of beliefs to price changes. The trade-off is illustrated in figure 3 , which shows the response of log prices to a wage shock in the demand-side learning environment. When the gain is low the shift in beliefs after the shock hits is insufficient for the effect of higher expected capital gains to outweigh the effect of the wage shock dying out. As a result, the shock does not propagate. In contrast, under high gain calibrations the shock is propagated through prices. However, owing to household beliefs placing a relatively larger weight on current shocks (represented through the $\Theta_{t}$ and $\rho_{t}$ terms in (26)), once the wage shock dies off $m_{t}$ is quick to readjust to fundamentals and $q_{t}$ returns to steady state faster than was the was the case under a low gain. This tight trade-off between the persistence and responsiveness of beliefs under demand-side learning implies that such frameworks can struggle to generate the kind of sustained price growth seen in the data without a similarly persistent set of shocks.

The credit supply problem in 3.2 introduces a complementary learning mechanism into the model. Shifts in expected $\log$ price growth, $\log m_{t}$, lead the lender to increase credit supply due to lower perceived default risk and higher expected payoffs in the event of default. As households are constrained this increases their demand for housing. As before, the shift in $m_{t}$ also pushes up the demand for housing through its effect on 
expected capital gains. Hence, shifts in subjective beliefs give rise to credit supply changes that complement the effect of demand-side learning on prices. The parallel channels through which learning operates in the full model can be illustrated as follows:

$$
q \uparrow \Longrightarrow m_{t} \uparrow \Longrightarrow\left\{\begin{array}{cc}
\text { Household: } & \mathbb{E}_{t}^{\mathcal{P}} \text { [Capital Gain] } \uparrow \\
\text { Lender: } & \left\{\begin{array}{c}
\operatorname{Pr}^{\mathcal{P}} \text { (Default) } \downarrow \\
\mathbb{E}_{t}^{\mathcal{P}} \text { (Default Value } \uparrow
\end{array}\right\} \Longrightarrow \theta_{t} \uparrow
\end{array}\right\} \Longrightarrow \text { Demand } \uparrow \Longrightarrow q \Uparrow
$$

Intuitively, the introduction of learning on the credit supply side should increase the persistence in the belief process. Following the an initial shock to prices and a shift in $m_{t}$, the subsequent change in prices should be greater as there is both a demand and credit supply response to the belief shift. This will imply that the change in $m_{t}$ in the second period following the shock will be greater than under demand-side learning and so on. As a result, for any level of responsiveness of beliefs to shocks the propagation cycle should be longer.

In order to explicitly show the influence of this parallel mechanism on the dynamics of household beliefs an approximate law of motion for $m_{t}$ is derived by combining (25) with the lender's decision rule $\theta\left(m_{t}\right)$. Taking a linear approximation yields

$$
\log m_{t} \approx \overbrace{\text { exp. capital gains }+ \text { updating }+ \text { credit supply }}^{\overbrace{\frac{\left\{1-g\left(1+\mu_{1}+\mu_{2} \frac{\partial \bar{\theta}}{\partial m}\right)\right\}}{\left\{1-g\left(\mu_{1}+\mu_{2} \frac{\partial \bar{\theta}}{\partial m}\right)\right\}}}^{\equiv P^{\prime}} \log m_{t-1}}+\mathbb{E}_{t}\left[D\left(g, \bar{\theta}, R, \bar{\rho}, \gamma_{c}\right) \cdot\left(\begin{array}{c}
\log \frac{h_{t}}{h_{t-1}} \\
\log \frac{\rho_{t+1}}{\rho_{t}}
\end{array}\right)\right]
$$

where $\mu_{1}, \mu_{2}<0^{29}$. The autoregressive coefficient $P^{\prime}$ now has the following properties

$$
\frac{d P^{\prime}}{d \partial \bar{\theta} / \partial m}>0 ; \frac{d\left(\operatorname{abs}\left(d P^{\prime} / d g\right)\right)}{d \partial \bar{\theta} / \partial m}<0
$$

While the autoregressive coefficient is decreasing in the gain as before, the effect of learning in credit supply

$$
\begin{aligned}
& { }^{29} \text { Combing the (24) with (3) and (2) yields } \\
& \qquad \begin{aligned}
\log \frac{q_{t}}{q_{t-1}}=\mu_{1} \log \frac{m_{t}}{m_{t-1}}+\mu_{2} \bar{\theta} \log \frac{\theta_{t}}{\theta_{t-1}}+\mu_{3} \log \frac{h_{t}}{h_{t-1}}+\mu_{4} \log \frac{\Gamma_{t+1}}{\Gamma_{t}}+\mu_{5} \log \frac{\Sigma_{t+1}}{\Sigma_{t}} \\
\mu_{0}=1-\rho-\left(\frac{1-\gamma_{c}}{\gamma_{c}}\right) \cdot\left(\frac{\bar{\theta}}{R}-\delta\right) ; \mu_{1}=\frac{1}{\mu_{0}} \cdot\left(\rho+\frac{\bar{\theta}}{R} \cdot\left(\frac{1-\gamma_{c}}{\gamma_{c}}\right)\right) \mu_{2}=\frac{1}{\mu_{0}} \cdot \frac{1}{R} \cdot\left(\frac{1-\gamma_{c}}{\gamma_{c}}\right) \\
\mu_{3}=-\frac{1}{\mu_{0}} \cdot\left(1-\rho+\left(1-\frac{\bar{\theta}}{R}\right)\left(\frac{1-\gamma_{c}}{\gamma_{c}}\right)\right) \mu_{4}=\frac{1}{\mu_{0}} \cdot\left(\rho-\frac{\bar{\theta}}{R}\right) \mu_{5}=\frac{\rho}{\mu_{0}}
\end{aligned}
\end{aligned}
$$


on beliefs is clear. First, increasing the elasticity of credit supply with respect to $m_{t}$ increases the persistence in $m_{t}$ conditional on the gain. Second, as the elasticity of credit supply with respect to $m_{t}$ increases the influence of the gain on persistence $P^{\prime}$ decreases. This is the key influence of the complementarity induced by two-sided learning. If lenders are sufficiently responsive to their beliefs in the full model, the trade-off in trying to generate beliefs that are both persistent and sensitive to price changes that exists in demand-side learning frameworks can be broken. Section 6 tests whether this is indeed the case in the calibrated model.

\section{Quantitative Results}

Following a number of papers in the literature the constant gain algorithm is modified for model simulations as follows:

$$
\ln m_{t}=\ln m_{t-1}+g\left(\sigma_{q}, \sigma_{\omega}\right) \cdot\left(\ln \frac{q_{t-1}}{q_{t-2}}-\ln m_{t-1}\right)
$$

This assumption avoids simultaneity between the determination of prices and beliefs, and significantly speeds up the computation ${ }^{30}$. Furthermore, in order to guarantee stability a constraint is imposed on the lenders credit supply choice when simulating the model: $\theta_{t} \leq \bar{\theta}$. This can be conceptualized as a regulatory constraint on LTV ratios. In practice, the model does not hit the constraint when simulating at business cycle frequencies. $\bar{\theta}$ is set equal to 1.05 .

\subsection{Interest Rates \& Boom-Bust in House Prices}

The paper now considers the model's ability to endogenously generate persistent growth in house prices consistent with the observed boom in US housing markets in the mid-2000s. Given the paucity of empirical evidence that identifies significant trends in housing market fundamentals during this period, it is desirable that models should be able to generate persistent price growth following a small set of shocks. This section evaluates the potential for interest rate movements in particular to generate boom-bust periods in the calibrated model.

In recent years there has been wide discussion about the extent to which monetary policy contributed to the 2008 financial crisis in general and to the house price boom more particularly. An argument commonly advanced in both the popular and academic literature is that persistently low interest rates encouraged excessive borrowing through the early 2000s. The ensuing effect of the credit expansion on demand for

\footnotetext{
${ }^{30}$ See Adam, Kuang, and Marcet (2011) and Eusepi and Preston (2011).
} 
Figure 4: Response of Log House Prices to Interest Rate Drop

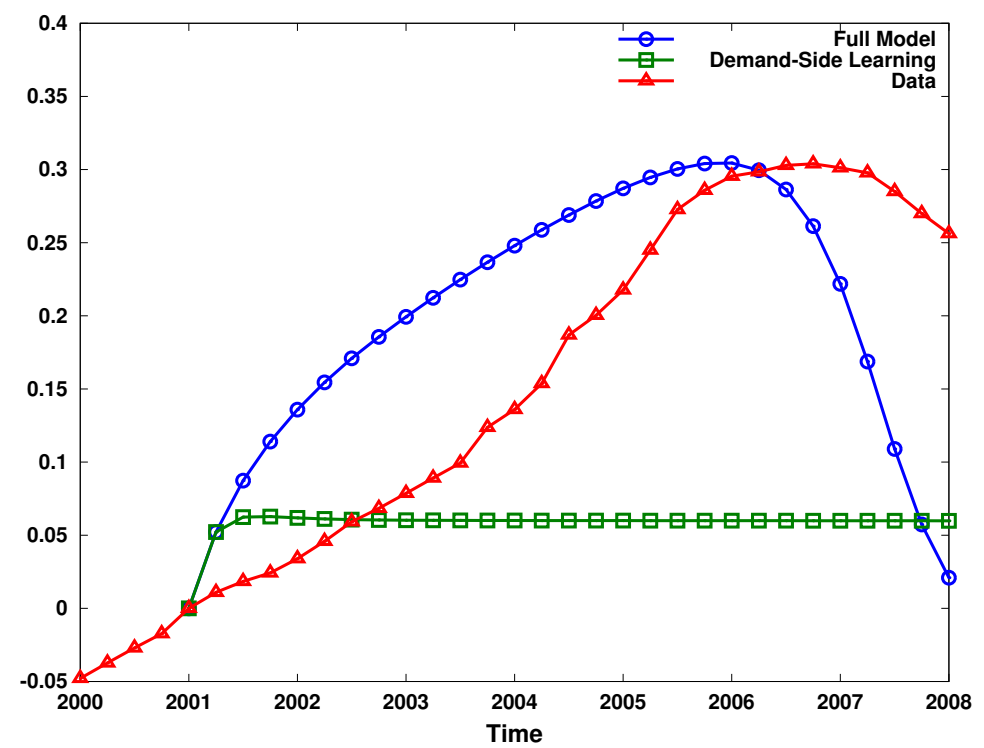

housing may have in turn generated appreciation in house prices over a near-10-year period. A growing empirical literature links interest rate movements with periods of financial instability. Hott and Jokipii (2012) show that over the past 30 years, across a sample of 14 OECD countries, periods of low interest rates Granger-cause deviations of house prices from fundamentals-implied levels (the authors' characterization of a bubble). In a similar vein, Ahearne et al. (2005) show that across advanced economies house price bubbles tend to be preceded by a period of loosening monetary policy.

The early 2000s saw a period of abrupt decreases in mortgage rates across the US economy. Beginning in late 2000 the 30-year conventional mortgage rate in the US began a 3\% drop, and thereafter remained relatively low until 2006. The rate drop coincided with an acceleration in the aggregate house price index for the US. In the environment presented in section 3.1, such a rate decrease not only drops the borrowing costs that households face, but also serves to relax their credit constraints. As discussed in section 5, the learning framework considered here gives the model strong internal propagation mechanisms by allowing for potentially large persistence in subjective beliefs without sacrificing the responsiveness of these beliefs to new information.

In order to investigate whether the calibrated model can explain the pattern of house prices in the 2000s the effect of an unanticipated drop in $R$ is considered. The model is simulated from steady state with an initial interest rate set equal to the mean 30-year conventional mortgage rate in the US from 1996 Q1 to 
2000 Q4. The drop in $R$ is calibrated to match the mean US mortgage rate from 2001 Q1 to 2006 Q4 $4^{31}$. Figure 4 plots the response of log prices to the unanticipated rate drop, together with both the response of prices when learning is restricted to the demand side of the housing market ${ }^{32}$ and the actual path of the FHFA All-Transaction House Price Index. Under demand-side learning the shift in the distribution of expected capital gains is insufficient to subsequently generate large shifts in housing demand. As a result the propagation of the interest rate shock in house prices is negligible. In the full model the shift in beliefs $m_{t}$ following the initial increase in prices generates an increase in credit supply relative to the market value of housing. As is clear in figure 4, this additional mechanism has a dramatic influence on the evolution of prices following the shock. The model can account for the full appreciation in US house prices in the early 2000s with total growth between 2001 Q1 and 2006 Q4 slightly overstating the level observed in the data. Furthermore, the model can explain much of the persistence in prices following 2001. Following 2001 Q1, price growth persists for 20 quarters in the model, compared with 22 quarters in the data series. Importantly, the model is also capable of capturing asymmetry in boom-bust cycles. Following the peak in the simulated price series in figure 4, prices collapse to the steady state level within 12 quarters.

Figure 5: Response of Log House Prices and Credit to Interest Rate Drop

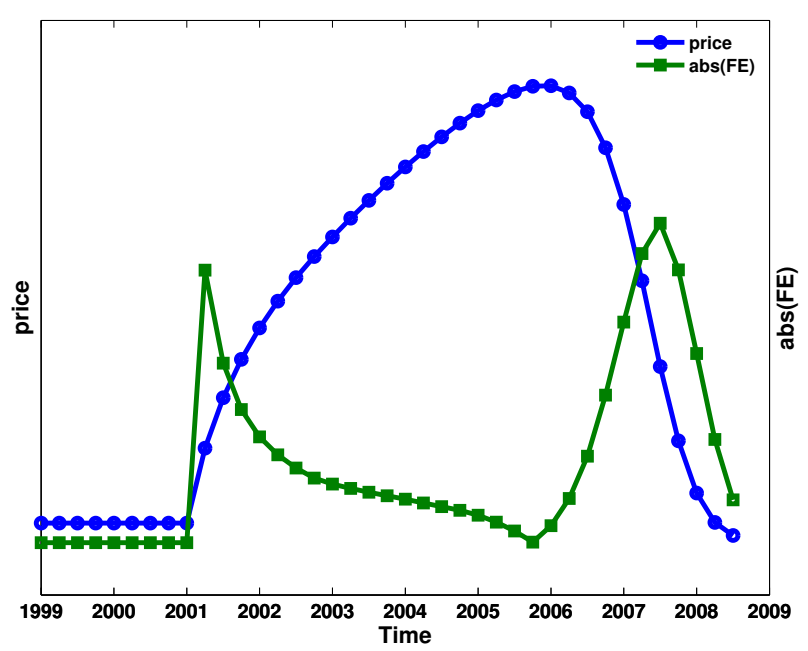

(a) House Price and Absolute Value of the 1-QuarterAhead Forecast Error

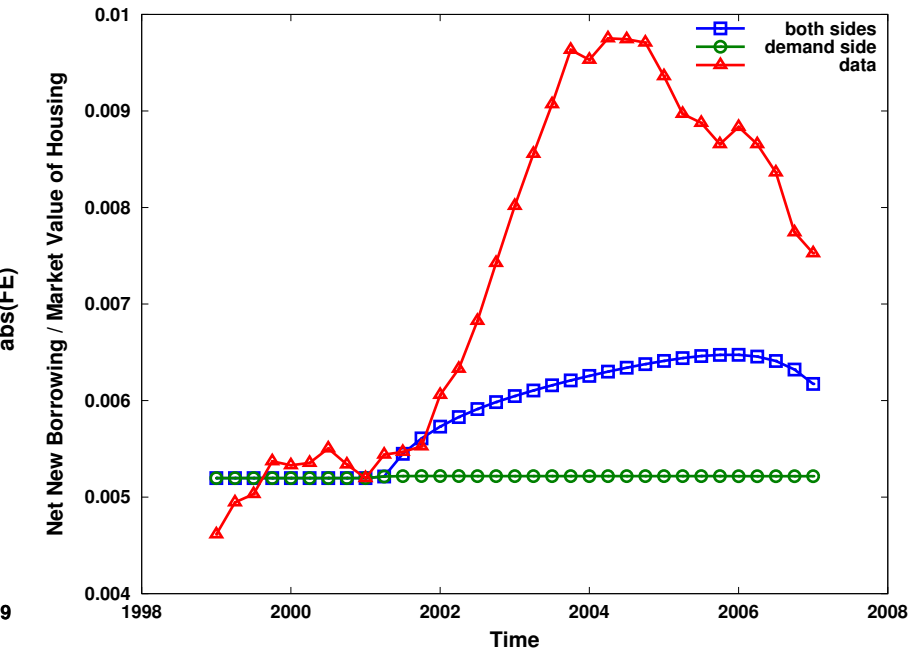

(b) Leverage

\footnotetext{
${ }^{31}$ This follows from an exercise carried out in Adam, Kuang, and Marcet (2011). A similar exercise can be found in Kuang (2014).

${ }^{32}$ In the "demand-side learning model" considered from here on, only households are assumed to have the beliefs specified in section 3.3.
} 
Two comments should be made about this result. First, the literature on learning has not yet reached a settled view on how to appropriately calibrate gain parameters in constant gain learning. As a result a wide range of values are found in the literature and the estimated gain in this paper sits in the high end of this spectrum. Second, as noted in section 4, the calibration of the model suffers from the necessity of imposing a relatively high value for $\delta_{h}$. In order to gauge the sensitivity of the price response to these assumptions, the previous exercise was carried out over a grid of $g$ and $\delta_{h}{ }^{33}$. Figure A.1 in appendix A plots the maximum deviation of log prices from steady state following the $R$ drop as well as the length of the propagation period (the number of quarters of positive price growth following the shock) over $\left(g, \delta_{h}\right)$. Conditional on a given $\delta_{h}$, decreasing the gain parameter actually increases the size of price growth following the interest rate shock. Similarly, increasing the depreciation rate on housing serves to augment rather than dampen price growth in the model. In both cases, changes in $\delta_{h}$ or $g$ from the values listed in table 1 have an ambiguous effect on the length of the propagation period. However, the finding that price growth persists for many quarters following the interest rate shock is robust to perturbations of either parameter in the neighborhood of the calibrated values.

As discussed in section 1, the available data on price forecasts suggest that agents' forecast errors tend to be largest following turning points in the price series. This is consistent with the model's response to the $R$ shock. The left hand panel of figure 5 plots the absolute value of the forecast error of log price growth in the model following the unanticipated rate drop. The large spike in forecast errors at the point of the interest rate drop drives the initial appreciation in expected price growth. As beliefs adjust to higher prices the magnitude of the forecast errors decreases. This slows the growth in $m_{t}$, and as a result growth in $q_{t}$, until forecast errors go to zero and the model hits a turning point. The ensuing collapse in the simulated prices and beliefs $m_{t}$ is driven by a series of large negative forecast errors. The model also captures comovements in house prices and household leverage.

The right hand panel in figure 5 plots a simulated series of household leverage measures. Because debt contracts are one period in length and the framework does not feature an occasionally binding constraint, the model abstracts from some dynamics of household debt. In order to make the data and model series comparable, the right hand panel in figure 5 plots net new mortgage borrowing as a fraction of the market value of housing stock in both the data and the model ${ }^{34}$. Consistent with evidence provided in figure 2,

\footnotetext{
${ }^{33}$ Note that for the different values of $g$ the priors and parameters of the lender's problem were recalculated as in section 4.

${ }^{34}$ Note, the series are normalized to 2001 Q1.
} 
the model generates increases in credit supply and household leverage concurrent with the takeoff in house prices. Under demand-side learning the growth in leverage is negligible. By contrast the full model can generate almost a third of the growth in the leverage measure seen in the data. Because the lender's problem is highly stylized, the leverage series tracks house prices closely following the shock. This is the result of the lenders' choice being predominantly a function of $m_{t}$ through the lender's credit supply problem outlined in section 3.2. Nevertheless, the framework suggests a potentially powerful mechanism for endogenously generating liberalizations in credit markets during price booms.

Table 2: Business Cycle Moments

\begin{tabular}{|c|c|c|c|c|c|}
\hline & \multicolumn{2}{|c|}{ Data } & \multicolumn{2}{|c|}{ Learning } & \multirow{2}{*}{$\begin{array}{c}\text { Rational } \\
\text { Expectations }\end{array}$} \\
\hline & $\begin{array}{c}\text { 1978Q1 - } \\
\text { 2014Q1 }\end{array}$ & $\begin{array}{c}\text { 1978Q1 - } \\
\text { 1990Q1 }\end{array}$ & $\begin{array}{c}\text { Demand-Side } \\
\text { Learning }\end{array}$ & $\begin{array}{c}\text { Full Learning } \\
\text { Model }\end{array}$ & \\
\hline \multicolumn{6}{|l|}{$\operatorname{std}(\cdot) / \operatorname{std}(y)$} \\
\hline$q$ & 7.686 & 2.488 & 1.715 & 2.452 & 0.598 \\
\hline$q \cdot h^{*}$ & 9.824 & 2.968 & 1.770 & 2.480 & 0.607 \\
\hline$f e\left(q / q_{-1}\right)$ & 1.367 & 1.367 & 0.556 & 0.652 & 0.334 \\
\hline$F$ & $\cdot$ & $\cdot$ & 0.849 & & 0.506 \\
\hline$\theta$ & 15.560 & 7.006 & $\cdot$ & 1.943 & $9 \times 10^{-4}$ \\
\hline \multicolumn{6}{|l|}{ skewness $(\cdot)$} \\
\hline$q$ & 1.118 & 0.381 & 0.016 & 0.195 & -0.102 \\
\hline$q \cdot h$ & 1.345 & 0.054 & 0.017 & 0.196 & -0.102 \\
\hline$f e\left(q / q_{-1}\right)$ & -0.074 & -0.074 & 0.016 & 0.065 & 0.016 \\
\hline$F$ & $\cdot$ & $\cdot$ & -0.028 & 0.152 & -0.011 \\
\hline$\theta$ & -0.021 & 0.208 & . & 0.178 & 0.086 \\
\hline
\end{tabular}

Reported moments are for log values. Simulation moments are taken from simulated sample of size 50000 quarters, with the first 1000 quarters dropped as burn-in. Reported data moments of one-quarter-ahead forecast errors are from CME data sample running from 2007Q1 to 2011Q1. Wage data, $y$, is detrended using a bandpass filter with frequency range $1 / 32$ to $1 / 8$ cycles per quarter.

* data for market value of housing stock taken from Davis and Heathcote (2007), see section 4 


\subsection{Capturing Cyclical Variation in Housing Markets}

In order to test whether the results in section 6.1 come at the expense of the the model's ability to capture normal cyclical variation in prices and forecast errors, several large-sample simulations are carried out. Table 2 shows moments for simulations of the full model as well as for the model when learning only takes place on the demand side of the housing market, and the model under rational expectations. Note that the presence of the mid-2000s price boom has a large effect on measured volatilities. Table 2 therefore includes data moments for a pre-boom sample covering 1978Q1 - 1990Q1 in order to gauge moments during 'normal' periods. Under rational expectations neither prices nor the market value of housing display anything like the volatility seen in the data. The standard deviation of each of these series, relative to wages, is only about $20-25 \%$ of that seen in the pre-boom sample. Furthermore, under rational expectations the relative standard deviation of the one-quarter-ahead forecast error of house price growth is a quarter of that measured in the data.

The introduction of bounded rationality on the demand side of the market significantly increases volatilities in the model, however the relative standard deviation of prices and the market value of housing remain $31 \%$ and $40 \%$ below their pre-boom data values. By contrast, the full two-sided learning model comes close to matching both of these moments. The model is able to capture almost all the observed volatility in prices and the vast majority the relative standard deviation in the market value of housing. The volatility of the housing stock is relatively low in the model. This is a result of the very simple framework governing the construction of new housing stock. As a result the model performs better in explaining price variation than it does variation in the market value of total housing stock. Introducing interaction between near-rational households and near-rational lenders similarly increases the volatility of forecast errors, with the relative standard deviation $17 \%$ higher under two-sided learning. While the model fails to capture the volatility in household leverage, the introduction of bounded rationality amongst lenders nevertheless produces an extreme increase in the volatility of $\theta$ relative to the rational expectations model (as a result there is also a large increase in the volatility of the foreclosure inventory).

In order to gauge the robustness of these findings, figure 6 plots the relative standard deviation of simulated prices and forecast errors in the model for different values of $g$. For each $g,\left\{\sigma_{0}, \sigma_{q}, \sigma_{\omega}, \mu, K\right\}$ is recalibrated in line with section 4. As can be seen, in the region of the value of $g$ found in section 4 the volatilities displayed by the model remain close to the data values listed in table 2. As is also clear in 
Table 3: Business Cycle Correlations

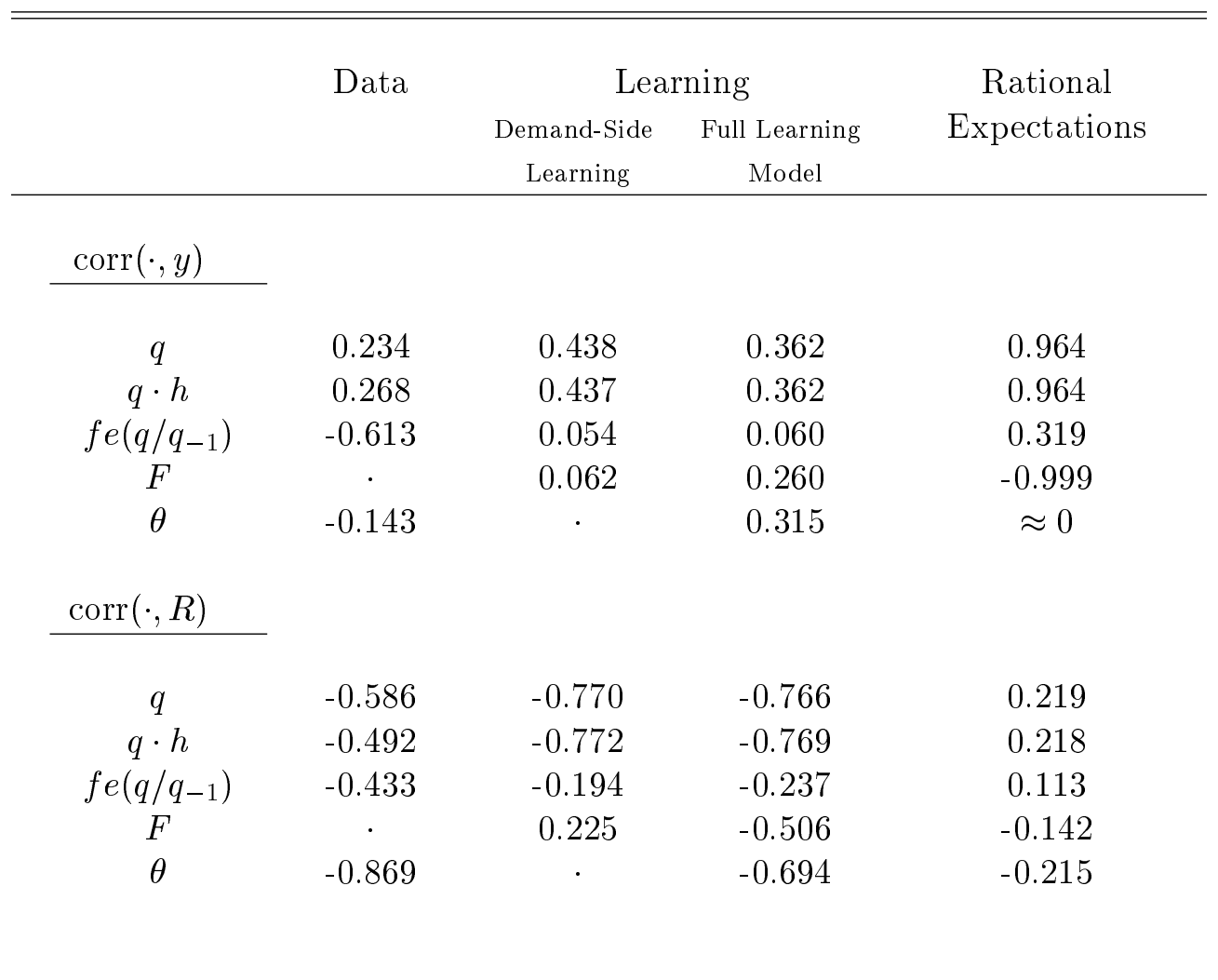

Reported moments are for log values. Simulation moments are taken from simulated sample of size 50000 quarters, with the first 1000 quarters dropped as burn-in. Reported data moments of one-quarter-ahead forecast errors are from CME data sample running from 2007Q1 to 2011Q1. Wage data, $y$, is detrended using a bandpass filter with frequency range $1 / 32$ to $1 / 8$ cycles per quarter.

table 2, the model provides a closer fit to the third moments measured in the data. Neither the rational expectations model nor the demand-side learning model can produce the positive skew observed in house prices and household leverage. The model also matches the observed skewness in the forecast error series.

Table 3 shows correlations between the simulated data and the exogenous processes $y$ and $R$. Given the literature indicating that interest rates have been a key driver of house prices over the past 30 years (see Hott and Jokipii (2012)) the correlations of simulated prices and forecast errors with $R$ are of particular interest. Both the rational expectations model and the model with only demand-side learning overstate the negative correlation between prices (and the market value of housing stock) and mortgage rates relative to the data. The introduction of learning amongst lenders has little effect on the measured value of this correlation. The full learning model also captures $55 \%$ of the observed negative correlation between $R$ and 
Figure 6: Standard Deviation of $q$ and $f e\left(q / q_{-1}\right)$ Relative to $y$

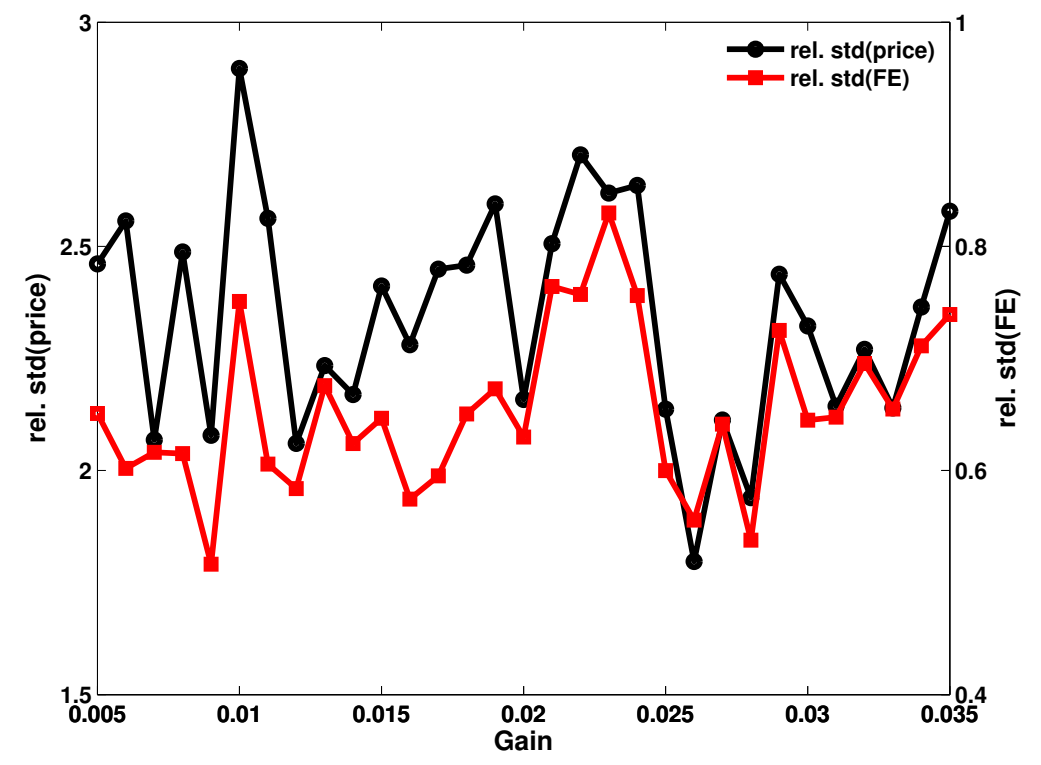

forecast errors, an improvement upon the demand-side learning model, and comes close to matching the observed correlation between $\theta$ and $R$. As can also be seen in table 3 , the full model can also capture the observed correlation between house prices (and the market value of housing stock) and wages.

Turning to the time-series properties of the model, figure 7 plots the periodogram of prices for the three models listed in tables 2 and 3. Under rational expectations house prices fail to display the level of low-frequency variation seen in the data. This problem is alleviated through the introduction of bounded rationality in the model. Both the full model as well as the model with only demand-side learning can capture the bulk of the low frequency (ie. less than 0.2 cycles per quarter) variation in the data, however the full learning model provides a marginally better fit to the data spectrum. Autocorrelations for forecast errors and $\theta$ are shown in table 4 . The full learning model matches the first order autocorrelation in forecast errors, however it overstates persistence in the series at higher lags. The learning model also overstates persistence in household leverage, however it significantly outperforms the rational expectations model in this regard.

In sum, the model developed here weakly dominates the demand-side learning model along the dimensions discussed. The model captures almost all of the volatility in house prices over the business cycle whilst providing a closer fit to observed correlations with market fundamentals. 
Table 4: Autocorrelation

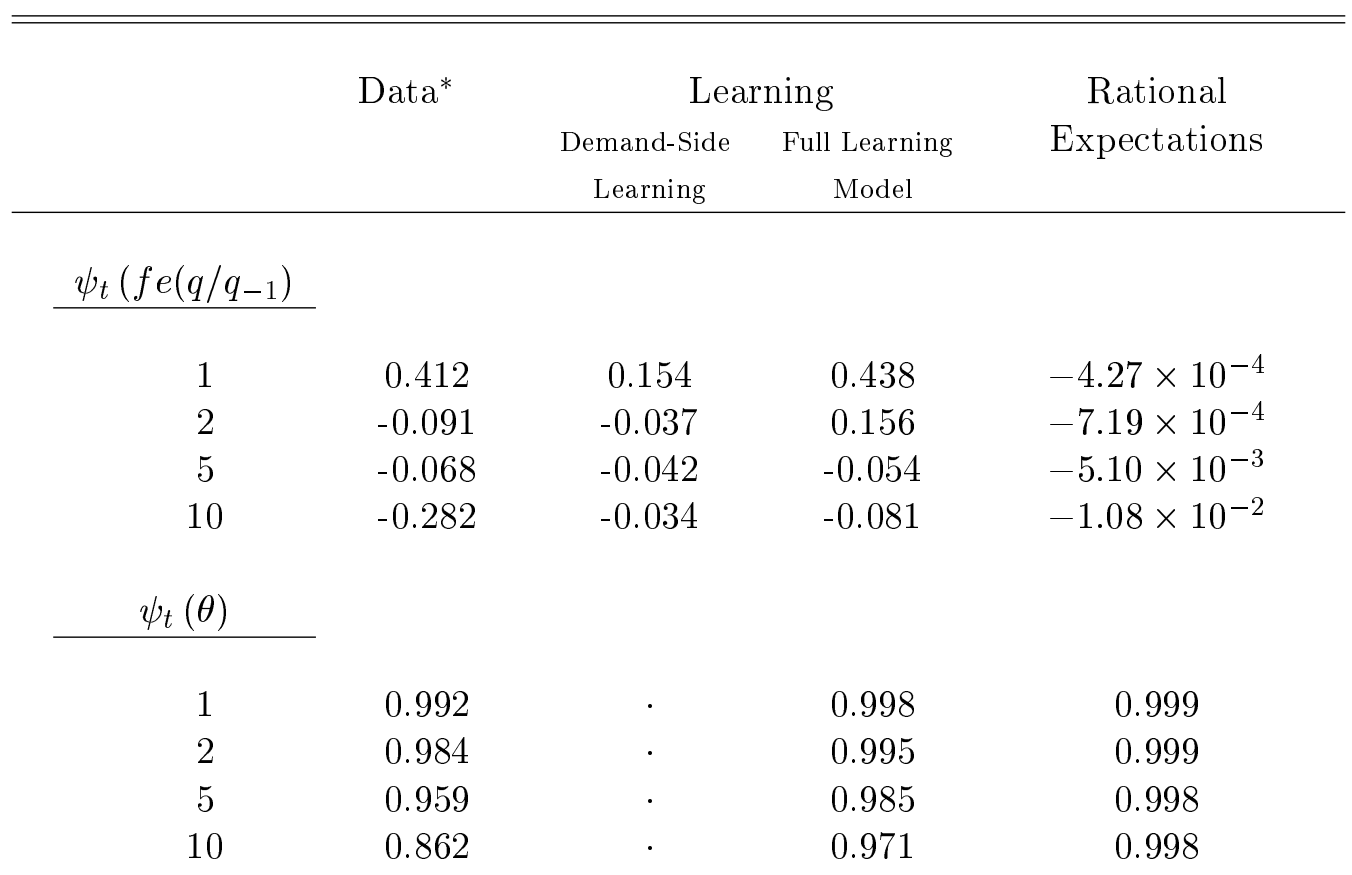

\footnotetext{
* autocorrelations for $\theta$ are taken on sample from 1978Q1-2014Q1

Reported moments are for log values. Simulation moments are taken from simulated sample of size 50000 quarters, with the first 1000 quarters dropped as burn-in. Reported data moments of one-quarter-ahead forecast errors are from CME data sample running from 2007Q1 to 2011Q1. Wage data, $y$, is detrended using a bandpass filter with frequency range $1 / 32$ to $1 / 8$ cycles per quarter.
}

\section{Conclusion}

This paper provides a framework for explaining asset price booms. A general equilibrium model with learning can quantitatively explain US house price growth in the 2000s and account for volatilities in house prices and forecast errors when agents learn subjective beliefs about prices. The model departs from established frameworks in allowing for bounded rationality amongst both households and the suppliers of credit. In demand-side learning models there exists a trade-off between generating subjective beliefs that are persistent and at the same time highly responsive to innovations. The interaction between the demand and credit supply sides of the market under learning boost the persistence in beliefs, thereby breaking this trade-off. A single permanent and unanticipated decrease in mortgage rates, consistent with the observed drop in US interest rates in the early 2000s, produces 20 quarters of price growth whilst capturing the 
Figure 7: Periodogram of Log House Prices

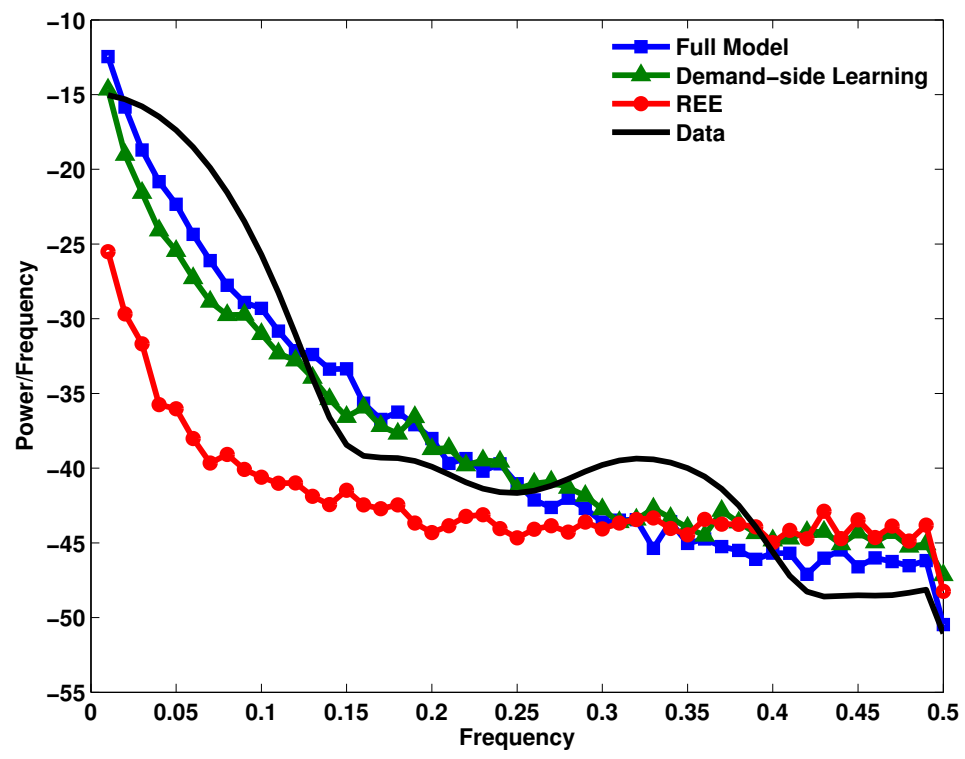

total growth in prices observed across the US. The model also outperforms both demand-side learning and rational expectations models in capturing key business cycle moments.

There are several further issues that can explored using the framework developed here. In particular, the paper has assumed homogeneous beliefs between households and credit suppliers, however this can be easily relaxed. The open economy assumption implies that interest rate movements in the model are exogenous. The model can be augmented to consider endogenous mortgage rates and the influence of movements in mortgage rate expectations amongst households. Similarly, a natural line of inquiry would be to augment the funding side of the lenders problem and consider the effects of uncertainty about financial risk. 


\section{References}

Adam, Klaus, Johannes Beutel, and Albert Marcet. 2014. "Stock Price Booms and Expected Capital Gains." Working Papers 14-12, University of Mannheim, Department of Economics.

Adam, Klaus, Pei Kuang, and Albert Marcet. 2011. "House Price Booms and the Current Account." NBER Macroeconomics Annual 26:77-122.

Adam, Klaus and Albert Marcet. 2010. "Booms and Busts in Asset Prices." IMES Discussion Paper Series 10-E-02, Institute for Monetary and Economic Studies, Bank of Japan.

—_ 2011. "Internal Rationality, Imperfect Market Knowledge and Asset Prices." Journal of Economic Theory 146:1224-1252.

Adam, Klaus, Albert Marcet, and Juan Pablo Nicolini. 2013. "Stock Market Volatiliy and Learning." Working Paper, Federal Reserve Bank of Minneapolis.

Ahearne, Alan G. et al. 2005. "Monetary Policy and House Prices: A Cross-Country Study." Board of Governors of the Federal Reserve System, International Finance Discussion papers, Number 841.

Boz, Ermine and Enrique G. Mendoza. 2014. "Financial innovation. the discovery of risk, and the US credit crises." Journal of Monetary Economics 62:1-22.

Branch, William A. 2014. "Imperfect Knowledge, Liquidity and Bubbles." Working Paper, University of California, Irvine.

Branch, William A. and Bruce McGough. 2011. "Bsiness Cycle Theory and Amplification with Heterogeneous Expectations." Economy Theory 47:395-421.

Branch, William A., Nicolas Petrosky-Nadeau, and Guillaume Rocheteau. 2014. "Financial Frictions, Housing Market, and Unemployment." Working Paper, University of California, Irvine.

Bulusu, Narayan, Jefferson Duarte, and Carles Vergaga-Alert. 2013. "Booms and Busts in Houst Prices Explained by Constraints in Housing Suppl." Working Paper 2013-18, Bank of Canada.

Burnside, Craig, Martin Eichenbaum, and Sergio Rebelo. 2011. "Understanding Booms and Busts in Housing Markets." Working Paper 16734, National Bureau of Economic Research.

Carceles-Poveda, Eva and Chryssi Giannitsarou. 2008. "Asset Pricing with Adaptive Learning." Review of Economic Dynamics 11:629-651.

Case, Karl E. and Robert J. Shiller. 2003. "Is there a Bubble in the Housing Market." Brookings Papers on Economic Activity 34:299-362.

Cellarier, Laurent. 2006. "Constant Gain Learning and Business Cycles." Journal of Macroeconomics 28:51-85.

__ 2008. "Least Squares Learning and Business Cycles." Journal of Economic Behavior EG Organization 68:553-564.

Cheng, Ing-Haw, Sahil Raina, and Wei Xiong. 2012. "Wall Street and the Housing Bubble." Working Paper, Ross School of Business, University of Michigan. 
Cho, In-Koo, Noah Williams, and Thomas J. Sargent. 2002. "Escaping Nash Inflation." Review of Economic Studies 69:1-40.

Christiano, Lawrence J. and Jonas D.M. Fisher. 2000. "Algorithms for solving dynamic models with occasionally binding constraints." Journal of Economic Dynamics and Control 24:1179-1232.

Chu, Yongqiang. 2014. "Credit Constraints, Inelastic Supply, and the Housing Boom." Review of Economic Dynamics 17:52-69.

Davis, Morris and Jonathan Heathcote. 2007. "The Price and Quantity of Residential Land in the United States." Journal of Monetary Economics 54 (8):2595-2620.

Eusepi, Stefano and Bruce Preston. 2011. "Expectations, Learning and Business Cycle Fluctuations." American Economic Review 101:2844-2872.

Evans, George W. and Seppo Honkapohja. 2001. Learning and Expectations in Macroeconomics. Princeton: Princeton University Press.

_ 2003. "Expectations and the Stability Problem for Optimal Monetary Policies." Review of Economic Studies 70:807-823.

Favilukis, Jack, Sydney C. Ludvigson, and Stijn Van Nieuwerburgh. 2010. "The Macroeconomic Effects of Housing Wealth, Housing Finance, and Limited Risk-Sharing in General Equilibrium." Worker Paper 15988, National Bureau of Economic Research.

Gelain, Paolo and Kevin J. Lansing. 2013. "House Prices, Expectations, and Time-Varying Fundamentals." Working Paper 2013-03, Federal Reserve Bank of San Francisco.

Glaeser, Edward L., Joseph Gyourko, and Albert Saiz. 2008. "Housing Supply and Housing Bubbles." Journal of Urban Economics 64:198-217.

Granziera, Eleonora and Sharon Kozicki. 2012. "House Price Dynamics: Fundamentals and Expectations." Working Paper 2012-12, Bank of Canada.

Hott, Christian and Terhi Jokipii. 2012. "Housing Bubbles and Interest Rates." Swiss National Bank, Working Paper.

Huang, Kevin X.D., Zheng Liu, and Tao Zha. 2009. "Learning, Adaptive Expectations and Technology Shocks." The Economic Journal :377-405.

Iacoviello, Matteo. 2011. "Housing Wealth and Consumption." Board of Governors of the Federal Reserve System, International Finance Discussion papers, Number 1027.

Justiniano, Alejandro, Giorgio Primiceri, and Andrea Tambalotti. 2015. "Household Leverage and Deleveraging." Review of Economic Dynamics 18 (1):3-20.

Kiyotaki, Nobuhiro, Alexander Michaelides, and Kalin NIkolov. 2011. "Winners and Losers in Housing Markets." Journal of Money, Credit and Banking 43:255-296.

Kiyotaki, Nobuhiro and John More. 1997. "Credit Cycles." The Journal of Political Economy 105 (2):211248.

Kreps, David M. 1998. "Anticipated Utility and Dynamic Choice." In Frontiers of Research in Economic Theory, edited by Donald P. Jacobs, Ehud Kalai, Morton I. Kamien, and Nancy L. Shwartz. Cambridge University Press, 242-274. 
Kuang, Pei. 2014. "A Model of Housing and Credit Cycles." European Economic Review :419-437.

Luzzetti, Matthew and Seth Neumuller. 2015. "Learning and the Dynamics of Consumer Unsercurted Debt and Bankruptcies." Working Paper, Wellesley College.

Marshall, Emily and Paul Shea. 2013. "Housing and Endogenous Default." Working Paper, University of Kentucky.

McCallum, Bennett T. 2007. "E-stability Vis-a-Vis Determinat Results for a Broad Class of Linear Rational Expectations Models." Journal of Economic Dynamics and Control 31:1376-1391.

Milani, Fabio. 2007. "Expectations, Learning and Macroeconomic Persistence." Journal of Monetary Economics 54:2065-2082.

Nakajima, Makoto. 2011. "Understanding House-Price Dynamics." Business Review Federal Reserve Bank of Philadelphia.

Pancrazi, Roberto and Mario Pietrunti. 2014. "Natural Expectations and Home Equity Extraction." Working Paper, University of Warwick.

Pastor, Lubos and Pietro Veronesi. 2006. "Was There a NASDAQ Bubble in the Late 1990s?" Journal of Financial Economics 81:61-100.

Piazzesi, Monika and Martin Schneider. 2009. "Momentum Traders in the Housing Market: Survey Evidence and a Search Model." Worker Paper 14669, National Bureau of Economic Research.

Preston, Bruce. 2005. "Learning about Monetary Policy Rules when Long-Horizon Expectations Matter." International Journal of Central Banking 1:81-126.

Saiz, Albert. 2010. "The Geographic Determinants of Housing Supply." The Quarterly Journal of Economics 125:1253-1296.

Sargent, Thomas J. 1999. The Conquest of American Inflation. Princeon University Press.

Sinha, Arunima. 2011. "Learning and the Yield Curve." Working Paper, Santa Clara University, Leavy School of Business.

Wheaton, Williams C. and Gleb Nechayev. 2010. "Residential Investment: a Sleeping Giant." Unpublished, MIT Center for Real Estate.

Williams, Noah. 2003. "Adaptive learning and business cycles." Unpublished, Princeton University.

—_. 2012. "Financial Instability via Adaptive Learning." Working Paper, University of Wisconsin Madison, Department of Economics.

Winkler, Fabian. 2015. "The Role of Learning for Asset Prices, Business Cycles and Monetary Policy." Working Paper, Board of Governors of the Federal Reserve.

Zhang, Cathy. 2012. "Bad News for News Shocks?" Working Paper, University of California, Irvine. 


\section{A Additional Figures}

Figure A.1: Maximum Log Price Deviation and Length of Propagation Following $R$ Drop

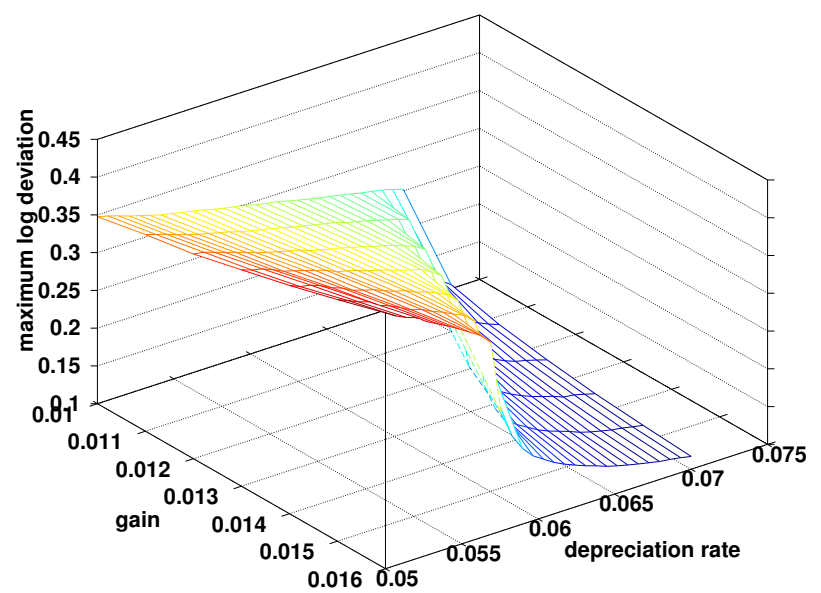

(a) Maximum Log Price Deviation

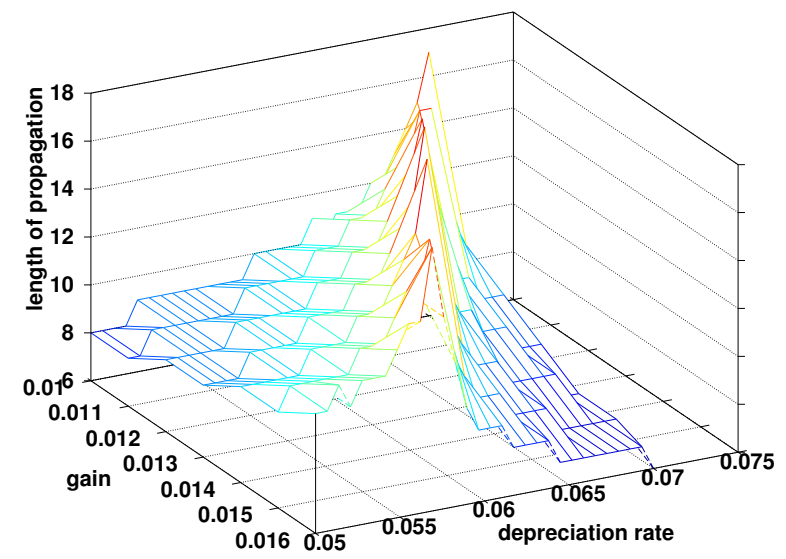

(b) Length of Propagation Following $R$ Drop 


\section{B Aggregation of Household Problem to Representative Agent}

This appendix outlines the aggregation of the household problem in section 3.1 to a representative agent. Assume that all notation is in terms of individual household $i$ in a heterogeneous agents economy. All agents are assumed to have the same information, preferences, credit constraint, etc... Assume that the households have access to a complete set of Arrow-Debreu securities in consumption goods. Also assume that the household has access to a security that is indexed to house prices (in other words, a security that delivers in units of housing). Assume that for both of these securities the household is exempt from obligations/payments if it defaults. For ease of notation, physical capital $k_{t}$ is omitted from the exposition, but its presence does not alter the steps outlined below.

- The budget constraint and credit constraint of of household $i$ are

$$
\begin{aligned}
c_{t}^{i}+q_{t} h_{t}^{i}+R b_{t-1}^{i}+p_{t}^{c} e_{c t}^{i}+p_{t}^{h} e_{h t}^{i} & =y_{t}^{i}+(1-\delta) h_{t-1}^{i}+b_{t}^{i}+e_{c t-1}^{i}+q_{t} e_{h t-1}^{i} \\
b_{t}^{i} & \leq\left(\frac{\theta}{R}\right) \tilde{\mathbb{E}}_{t}\left[q_{t+1}\right] h_{t}^{i} \equiv \tilde{Q}_{t} h_{t}^{i}
\end{aligned}
$$

these imply

$$
c_{t}^{i}+\left(q_{t}-\tilde{Q}_{t}\right) h_{t}^{i}=\tilde{y}_{t}^{i}+\left\{(1-\delta) q_{t}-R \tilde{Q}_{t-1}\right\} h_{t-1}^{i}
$$

where

$$
\tilde{y}_{t}^{i}=y_{t}^{i}-p_{t}^{c} e_{c t}^{i}-p_{t}^{h} e_{h t}^{i}+q_{t} e_{h t-1}^{i}+e_{c t-1}^{i}
$$

- Let

$$
1-\Gamma_{t}=\operatorname{Pr}\left(\frac{q_{t}}{q_{t-1}}<\zeta_{t}^{i} \frac{\theta}{1-\delta}\right)=\operatorname{Pr}\left(\text { Default } \mid \frac{q_{t}}{q_{t-1}}\right)
$$

- If the household defaults, it loses its stock of housing and no longer has to repay its debt $b_{t-1}$

- The household's maximization problem can be written as follows

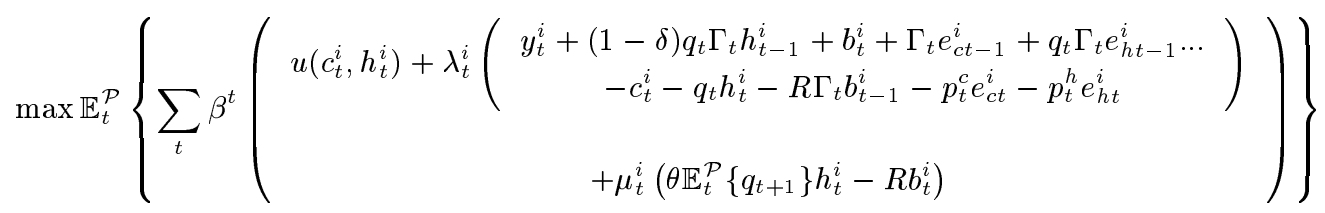

- The first order conditions for this problem are

$$
\begin{aligned}
p_{t}^{c} & =\beta \cdot \mathbb{E}_{t}^{\mathcal{P}}\left[\frac{\lambda_{t+1}^{i}}{\lambda_{t}^{i}} \Gamma_{t+1}\right] \\
p_{t}^{h} & =\beta \cdot \mathbb{E}_{t}^{\mathcal{P}}\left[\frac{\lambda_{t+1}^{i}}{\lambda_{t}^{i}} \Gamma_{t+1} q_{t+1}\right] \\
\lambda_{t}^{i} & =u_{c}\left(c_{t}^{i}, h_{t}^{i}\right) \equiv u_{c}^{i}(t) \\
\mu_{t}^{i} & =\frac{\lambda_{t}^{i}}{R}-\beta \lambda_{t+1}^{i} \Gamma_{t+1} \\
q_{t} \lambda_{t}^{i} & =u_{h}^{i}(t)+\mu_{t}^{i} \theta q_{t+1}+\beta(1-\delta) \lambda_{t+1}^{i} q_{t+1} \Gamma_{t+1}
\end{aligned}
$$




$$
\Longrightarrow q_{t}=\frac{u_{h}^{i}(t)}{u_{c}^{i}(t)}+\mathbb{E}_{t}^{\mathcal{P}}\left[\left(\beta(1-\delta) \cdot \frac{\lambda_{t+1}^{i}}{\lambda_{t}^{i}} \cdot \Gamma_{t+1}+\frac{\theta}{R}\right) \cdot q_{t+1}-\beta \theta\left(\mathbb{E}_{t}^{\mathcal{P}} q_{t+1}\right) \frac{\lambda_{t+1}^{i}}{\lambda_{t}^{i}} \Gamma_{t+1}\right]
$$

- From the securities market:

$$
\begin{aligned}
& p_{t}^{c}=\beta \cdot \mathbb{E}_{t}^{\mathcal{P}}\left[\frac{\lambda_{t+1}^{i}}{\lambda_{t}^{i}} \Gamma_{t+1}\right]=\beta \cdot \mathbb{E}_{t}^{\mathcal{P}}\left[\frac{\lambda_{t+1}^{j}}{\lambda_{t}^{j}} \Gamma_{t+1}\right] \\
& p_{t}^{h}=\beta \cdot \mathbb{E}_{t}^{\mathcal{P}}\left[\frac{\lambda_{t+1}^{i}}{\lambda_{t}^{i}} \Gamma_{t+1} q_{t+1}\right]=\beta \cdot \mathbb{E}_{t}^{\mathcal{P}}\left[\frac{\lambda_{t+1}^{j}}{\lambda_{t}^{j}} \Gamma_{t+1} q_{t+1}\right]
\end{aligned}
$$

- So these markets imply that the price of consumption and default-weighted housing is the same for all agents

- Rewrite the budget constraint, and combine with the assumption that the borrowing constraint binds

$$
\begin{aligned}
c_{t}^{i}+q_{t} h_{t}^{i}+R \tilde{Q}_{t-1} h_{t-1}^{i} & =\tilde{y}_{t}^{i}+(1-\delta) q_{t} h_{t-1}^{i}+\tilde{Q}_{t} h_{t}^{i} \\
\Longrightarrow c_{t}^{i}+\left(q_{t}-\tilde{Q}_{t}\right) h_{t}^{i} & =\tilde{y}_{t}^{i}+\left((1-\delta) q_{t}-R \tilde{Q}_{t-1}\right) h_{t-1}^{i}
\end{aligned}
$$

- From the household Euler

$$
\begin{aligned}
q_{t}= & \frac{1-\gamma_{c}}{\gamma_{c}} \cdot \frac{c_{t}^{i}}{h_{t}^{i}}+\beta(1-\delta) \underbrace{\mathbb{E}_{t}^{\mathcal{P}}\left[\frac{\lambda_{t+1}^{i}}{\lambda_{t}^{i}} \Gamma_{t+1} q_{t+1}\right]}_{\text {common across agents }}-\beta \theta\left(\mathbb{E}_{t}^{\mathcal{P}} q_{t+1}\right) \underbrace{\mathbb{E}_{t}^{\mathcal{P}}\left[\frac{\lambda_{t+1}^{i}}{\lambda_{t}^{i}} \Gamma_{t+1}\right]}_{\text {comon across agents }} \cdots \\
& +\underbrace{\frac{\theta}{R} \mathbb{E}_{t}^{\mathcal{P}}\left[q_{t+1}\right]}_{\tilde{Q}_{t}} \\
\Longrightarrow \frac{c_{t}^{i}}{h_{t}^{i}}= & \underbrace{\frac{1-\gamma_{c}}{\gamma_{c}}\left\{q_{t}-\tilde{Q}_{t}-\beta(1-\delta) \mathbb{E}_{t}^{\mathcal{P}}\left[\frac{\lambda_{t+1}^{i}}{\lambda_{t}^{i}} \Gamma_{t+1} q_{t+1}\right]+\beta \theta\left(\mathbb{E}_{t}^{\mathcal{P}} q_{t+1}\right) \mathbb{E}_{t}^{\mathcal{P}}\left[\frac{\lambda_{t+1}^{i}}{\lambda_{t}^{i}} \Gamma_{t+1}\right]\right\}}_{\equiv B_{t}, \text { common across agents }} \\
\Longrightarrow c_{t}^{i}= & B_{t} h_{t}^{i}
\end{aligned}
$$

- Substitute this into the modified budget constraint (46)

$$
\begin{aligned}
c_{t}^{i}+\left(q_{t}-\tilde{Q}_{t}\right) h_{t}^{i} & =\tilde{y}_{t}^{i}+\left((1-\delta) q_{t}-R \tilde{Q}_{t-1}\right) h_{t-1}^{i} \\
\Longrightarrow c_{t}^{i}+\left(q_{t}-\tilde{Q}_{t}\right) B_{t}^{-1} c_{t}^{i} & =\tilde{y}_{t}^{i}+\left((1-\delta) q_{t}-R \tilde{Q}_{t-1}\right) h_{t-1}^{i} \\
\Longrightarrow\left(1+\left(q_{t}-\tilde{Q}_{t}\right) B_{t}^{-1}\right) c_{t}^{i} & =\tilde{y}_{t}^{i}+\left((1-\delta) q_{t}-R \tilde{Q}_{t-1}\right) h_{t-1}^{i} \\
\Longrightarrow\left(1+\left(q_{t}-\tilde{Q}_{t}\right) B_{t}^{-1}\right) \sum_{i} c_{t}^{i} & =\sum_{i} \tilde{y}_{t}^{i}+\left((1-\delta) q_{t}-R \tilde{Q}_{t-1}\right) \sum_{i} h_{t-1}^{i}
\end{aligned}
$$


- Note that

$$
\begin{aligned}
\sum_{i} c_{t}^{i} & =C_{t} \\
\sum_{i} h_{t}^{i} & =H_{t} \\
\sum_{i} \tilde{y}_{t}^{i} & =\sum_{i}\left(y_{t}^{i}-p_{t}^{c} e_{c t}^{i}-p_{t}^{h} e_{h t}^{i}+q_{t} e_{h t-1}^{i}+e_{c t-1}^{i}\right) \\
& =Y_{t}-p_{t}^{c} \underbrace{\sum_{i} e_{c t}^{i}}_{=0}-p_{t}^{h} \underbrace{\sum_{i} e_{h t}^{i}}_{=0}+\underbrace{q_{t} e_{i}^{i} e_{h t-1}^{i}}_{=0}+\underbrace{\sum_{i} e_{c t-1}^{i}}_{=0}
\end{aligned}
$$

where the zeros are the result of market clearing in securities

$$
\Longrightarrow\left(1+\left(q_{t}-\tilde{Q}_{t}\right) B_{t}^{-1}\right) C_{t}=Y_{t}+\left((1-\delta) q_{t}-R \tilde{Q}_{t-1}\right) H_{t-1}
$$

which is equivalent to a representative agents' choice 


\section{Solving the Household Problem}

The solution to the household problem is computed using a parameterized expectations algorithm (PEA). Rewriting the household Euler (17) in simplified notation

$$
q_{t}-\frac{u_{h}(t)}{u_{c}(t)}=\mathbb{E}_{t}^{\mathcal{P}}\left[\Omega\left(q_{t+1}, c_{t+1}, h_{t+1}\right) \mid c_{t}, h_{t}, b_{t}, q_{t}, m_{t}, \theta_{t}, y_{t}, R_{t}\right]
$$

The expectation on the right hand side is approximated as

$$
\exp \left(e\left(X_{t}, \gamma\right)\right)
$$

The basis functions for $e(\cdot)$ are the Chebyshev polynomials. The vector of state variables for the household, $X_{t}$, is $\left(h_{t-1}, k_{t-1}, q_{t}, m_{t}, \theta_{t}, y_{t}, R_{t}\right)^{35}$. Define $\gamma$ to be a coefficient vector. The order of the approximation along each dimension is given by $\left(r_{h}, r_{k}, r_{q}, r_{m}, r_{\theta}, r_{y}, r_{\theta}\right)$, hence $\gamma$ is an $r_{h} \times r_{k} \times r_{q} \times r_{m} \times r_{\theta} \times r_{y} \times r_{\theta}$ vector. Let $\psi_{i}(x)$ denote the Chebyshev polynomial of order $i$ evaluated at $x$. Because the Chebyshev polynomials are defined on $[-1,1]$ the state variables are rescaled according to

$$
\tilde{x}=2 \frac{x-\bar{x}}{\bar{x}-\underline{x}}-1 \in[-1,1]
$$

The approximating function $e\left(X_{t}, \gamma\right)$ can be written

$$
\begin{aligned}
e((h, k, q, m, \theta, y, R), \gamma) & =T(h, k, q, m, \theta, y, R) \gamma \\
& =\left(T_{h}(h) \otimes T_{k}(k) \otimes T_{q}(q) \otimes T_{m}(m) \otimes T_{\theta}(\theta) \otimes T_{y}(y) \otimes T_{R}(R)\right) \gamma
\end{aligned}
$$

where $T_{x}(x)=\left(\psi_{0}(\tilde{x}), \psi_{1}(\tilde{x}), \ldots, \psi_{r_{x}}(\tilde{x})\right)$

The coefficient vector $\gamma$ is solved by appealing to the Chebyshev interpolation theorem and setting the approximating function $e(\cdot)$ to be exact at the Chebyshev nodes. $\gamma$ therefore solves the system

$$
\exp \left(\mathbb{E}_{t}^{\mathcal{P}}[\Omega(\cdot)]\right)-e((h, k, q, m, \theta, y, R), \gamma)=0 \forall \text { vectors of nodes }(h, k, q, m, \theta, y, R)
$$

which is an $r_{h} \times r_{k} \times r_{q} \times r_{m} \times r_{\theta} \times r_{y} \times r_{\theta}$ system of equations with $r_{h} \times r_{k} \times r_{q} \times r_{m} \times r_{\theta} \times r_{y} \times r_{\theta}$ unknowns. (53) is solved by an iterative procedure. Let $\hat{x}$ denote the $r_{x}$-vector of Chebyshev nodes along dimension $x$ and $\hat{X}=\hat{h} \times \hat{k} \times \hat{q} \times \hat{m} \times \hat{\theta} \times \hat{y} \times \hat{R}$

1. Start from an initial guess $\gamma_{0}$

2. Compute the vector $e\left(\cdot, \gamma_{0}\right)$ for all Chebyshev nodes $\hat{h} \times \hat{k} \times \hat{q} \times \hat{m} \times \hat{\theta} \times \hat{y} \times \hat{R}$ using (52)

$$
\begin{aligned}
e\left(\hat{h} \times \hat{k} \times \hat{q} \times \hat{m} \times \hat{\theta} \times \hat{y} \times \hat{R}, \gamma_{0}\right) & =T(\hat{h}, \hat{k}, \hat{q}, \hat{m}, \hat{\theta}, \hat{y}, \hat{R}) \cdot \gamma_{0} \\
& \equiv B \cdot \gamma_{0}
\end{aligned}
$$

3. Given $e\left(X, \gamma_{0}\right)$ one can back out a corresponding vector of choice variables $\left(c_{t}, h_{t}, b_{t}, k_{t}\right)$ from the

\footnotetext{
${ }^{35}$ In order to limit the size of the space the following approximation is applied $b_{t} \approx \frac{\theta_{t}}{R_{t}} q_{t} m_{t} h_{t}$.
} 
model equations outlined in section 3.1, call this $v\left(X, \gamma_{0}\right)$. Compute the expectation $\mathbb{E}_{t}^{\mathcal{P}}[\Omega(\cdot)]$ at all the Chebyshev nodes using a Gaussian quadrature, call this vector $Y\left(\hat{X}, \gamma_{0}\right)$,

$$
Y\left(\hat{X}, \gamma_{0}\right)=\int \Omega\left(q_{t+1}, c_{t+1}\left(v\left(\hat{X}, \gamma_{0}\right)\right), h_{t+1}\left(v\left(\hat{X}, \gamma_{0}\right)\right) \mid \hat{X}, v\left(\hat{X}, \gamma_{0}\right)\right) d F\left(y_{t+1}, q_{t+1} \mid q_{t}, y_{t}, \mathcal{P}\right)
$$

4. Compute

$$
\gamma^{*}=\left(B^{\prime} B\right)^{-1} B^{\prime} \log Y\left(\hat{X}, \gamma_{0}\right)
$$

5. Update the guess

$$
\gamma_{1}=\omega \gamma^{*}+(1-\omega) \gamma_{0}
$$

for $\omega \in(0,1)^{36}$

6. Repeat $1-5$ until convergence ${ }^{37}$

\footnotetext{
${ }^{36}$ The procedure fails to converge when $\gamma_{1}=\gamma^{*}$, necessitating this step.

${ }^{37}$ Further details on such methods can be found in Christiano and Fisher (2000).
} 


\section{Data Appendix}

US. Bureau of Economic Analysis, Compensation of employees: Wages and salaries [A576RC1Q027SBEA], retrieved from FRED, Federal Reserve Bank of St. Louis, https://research.stlouisfed.org/fred2/series/A576RC1Q027SBEA/

US. Bureau of Labor Statistics, Consumer Price Index for All Urban Consumers: All Items Less Food \& Energy [CPILFENS], retrieved from FRED, Federal Reserve Bank of St. Louis, https://research.stlouisfed.org/fred2/series/CPILFENS/, August 1, 2015.

US. Bureau of Economic Analysis, Personal Consumption Expenditures [PCECA], retrieved from FRED, Federal Reserve Bank of St. Louis, https://research.stlouisfed.org/fred2/series/PCECA/, August 1, 2015.

US. Bureau of Economic Analysis, Personal consumption expenditures: Services: Housing: Imputed rental of owner-occupied nonfarm housing [DOWNRC1A027NBEA], retrieved from FRED, Federal Reserve Bank of St. Louis, https://research.stlouisfed.org/fred2/series/DOWNRC1A027NBEA/, August 1, 2015.

US. Bureau of Economic Analysis, Shares of gross domestic product: Personal consumption expenditures: Durable goods [DDURRE1A156NBEA], retrieved from FRED, Federal Reserve Bank of St. Louis, https://research.stlouisfed.org/fred2/series/DDURRE1A156NBEA/, August 1, 2015.

US. Bureau of Economic Analysis, Shares of gross domestic product: Personal consumption expenditures: Nondurable goods [DNDGRE1A156NBEA], retrieved from FRED, Federal Reserve Bank of St. Louis, https://research.stlouisfed.org/fred2/series/DNDGRE1A156NBEA/, August 1, 2015.

US. Bureau of Economic Analysis, Shares of gross domestic product: Personal consumption expenditures: Services [DSERRE1A156NBEA], retrieved from FRED, Federal Reserve Bank of St. Louis, https://research.stlouisfed.org/fred2/series/DSERRE1A156NBEA/, August 1, 2015.

Freddie Mac, 30-Year Fixed Rate Mortgage Average in the United States [MORTGAGE30US], retrieved from FRED, Federal Reserve Bank of St. Louis, https://research.stlouisfed.org/fred2/series/MORTGAGE30US/, August 1, 2015

US. Federal Housing Finance Agency, All-Transactions House Price Index for the United States [USSTHPI], retrieved from FRED, Federal Reserve Bank of St. Louis, https://research.stlouisfed.org/fred2/series/USSTHPI/, August 1, 2015.

Board of Governors of the Federal Reserve System (US), Households and Nonprofit Organizations; Credit Market Instruments; Asset, Level [HSTCMAHDNS], retrieved from FRED, Federal Reserve Bank of St. Louis, https://research.stlouisfed.org/fred2/series/HSTCMAHDNS/, August 1, 2015.

Board of Governors of the Federal Reserve System (US), Households and Nonprofit Organizations; Credit Market Instruments; Liability, Level [CMDEBT], retrieved from FRED, Federal Reserve Bank of St. 
Louis,

https://research.stlouisfed.org/fred2/series/CMDEBT/, August 1, 2015.

Board of Governors of the Federal Reserve System (US), Real Gross Domestic Product [GDPC1], retrieved from FRED, Federal Reserve Bank of St. Louis, https://research.stlouisfed.org/fred2/series/GDPC1/, August 1, 2015.

Board of Governors of the Federal Reserve System (US), Households and Nonprofit Organizations; total mortgages; asset, Level [HNOTMAQ027S], retrieved from FRED, Federal Reserve Bank of St. Louis, https://research.stlouisfed.org/fred2/series/HNOTMAQ027S/, August 1, 2015.

Board of Governors of the Federal Reserve System (US), Households and Nonprofit Organizations; total mortgages; liability [HNOTMLQ027S], retrieved from FRED, Federal Reserve Bank of St. Louis, https://research.stlouisfed.org/fred2/series/HNOTMLQ027S/, August 1, 2015.

Board of Governors of the Federal Reserve System (US), Households and Nonprofit Organizations; Credit Market Instrutments; Asset, Level [CMIABSHNO], retrieved from FRED, Federal Reserve Bank of St. Louis, https://research.stlouisfed.org/fred2/series/CMIABSHNO/, August 1, 2015.

Board of Governors of the Federal Reserve System (US), Households and Nonprofit Organizations; Home Mortgages; Liability [HMLBSHNO], retrieved from FRED, Federal Reserve Bank of St. Louis, https://research.stlouisfed.org/fred2/series/HMLBSHNO/, August 1, 2015.

Board of Governors of the Federal Reserve System (US), Households; Owner's Equity in Real Estate as a Percentage of Household Real Estate, Level [HOEREPHRE], retrieved from FRED, Federal Reserve Bank of St. Louis, https://research.stlouisfed.org/fred2/series/HOEREPHRE/, August 1, 2015.

Board of Governors of the Federal Reserve System (US), Households and Nonprofit Organizations; Credit Market Instruments; Liability, level [HSTCMDODNS], retrieved from FRED, Federal Reserve Bank of St. Louis, https://research.stlouisfed.org/fred2/series/HSTCMDODNS/, August 1, 2015.

Board of Governors of the Federal Reserve System (US), Households; Owner's Equity in Real Estate, Level [OEHRENWBSHNO], retrieved from FRED, Federal Reserve Bank of St. Louis, https://research.stlouisfed.org/fred2/series/OEHRENWBSHNO/, August 1, 2015.

Board of Governors of the Federal Reserve System (US), Delinquency Rate On Single-Family Residential Mortgages, Booked In Domestic Offices, All Commercial Banks [DRSFRMACBS], retrieved from FRED, Federal Reserve Bank of St. Louis, https://research.stlouisfed.org/fred2/series/DRSFRMACBS/, August 1, 2015.

S\&P Dow Jones Indices LLC, S\&P/Case-Shiller 10-City Composite Home Price Index [SPCS10RNSA], retrieved from FRED, Federal Reserve Bank of St. Louis, https://research.stlouisfed.org/fred2/series/SPCS10RNSA/, August 1, 2015. 
Davis, Morris A. and Jonathan Heathcote, 2007, "The Price and Quantity of Residential Land in the United States," Journal of Monetary Economics, vol. 54 (8), p. 2595-2620; data located at Land and Property Values in the U.S., Lincoln Institute of Land Policy http://www.lincolninst.edu/resources/

Saiz, Albert. 2010. "The Geographic Determinants of Housing Supply," The Quarterly Journal of Economics 125: 1253-1296.

U.S. Dept. of Commerce, Bureau of the Census. AMERICAN HOUSING SURVEY, 2005: NATIONAL MICRODATA. ICPSR04593-v1. Washington, DC: U.S. Dept. of Commerce, Bureau of the Census [producer], 2006. Ann Arbor, MI: Inter-university Consortium for Political and Social Research [distributor], 2007-06-13. http://doi.org/10.3886/ICPSR04593.v1

Bloomberg L.P. CME Case Shiller Home Price Futures 1/5/2007 to 1/2/2015. Retrieved May 20, 2015 from Bloomberg database. 